\title{
Chemical biology of inflammatory cytokine signaling
}

\author{
Takao Kataoka
}

Pro-inflammatory cytokines, such as tumor necrosis factor- $\alpha$ and interleukin-1, trigger the signal transduction pathway leading

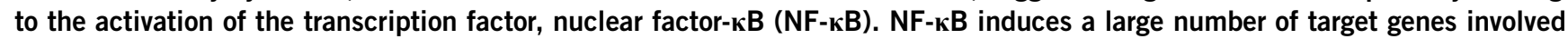
in many biological processes, such as inflammation, immunity, cell survival, cell death and carcinogenesis. As therapeutic agents for inflammatory diseases and cancer, as well as bioprobes for the characterization of intracellular biological response and cell function, a large number of natural and synthetic small molecules have been identified to inhibit the activation of the NF-кB signaling pathway. This review focuses on recent progress in the identification and biological properties of small molecules targeting the NF-кB signaling pathway induced by pro-inflammatory cytokines.

The Journal of Antibiotics (2009) 62, 655-667; doi:10.1038/ja.2009.98; published online 16 October 2009

Keywords: cardenolide glycosides; epoxyquinoids; IкB kinase inhibitors; protein synthesis inhibitors; sesquiterpene lactones

\section{INTRODUCTION}

Pro-inflammatory cytokines, such as tumor necrosis factor (TNF)- $\alpha$ and interleukin-1 (IL-1), trigger the activation of the transcription factor nuclear factor- $\kappa \mathrm{B}(\mathrm{NF}-\kappa \mathrm{B})$, thereby inducing a variety of genes involved in inflammation, innate and adaptive immunity, cell survival and cell death, as well as cancer development and progression (Figure 1). ${ }^{1,2}$ The NF- $\kappa \mathrm{B}$ family of transcription factors has five members, p65 (RelA), RelB, c-Rel, p105/p50 (NF-кB1) and p100/ p52 (NF- $\kappa$ B2), which share an N-terminal Rel homology domain responsible for DNA binding as well as homo- and hetero-dimerization, whereas a transcription activation domain is present only in p65, RelB and c-Rel (Figure 2a). ${ }^{3,4}$ Both NF- $\kappa B$ hetero- and homo-dimers are able to bind to $\kappa \mathrm{B}$ sites located in target genes and regulate their transcriptional activation. ${ }^{3,4}$ In unstimulated cells, NF- $\kappa B$ dimers, such as the p65/p50 heterodimer, are associated with the inhibitor of NF- $\kappa \mathrm{B}$ (I $\kappa \mathrm{B})$ family proteins, such as $\mathrm{I} \kappa \mathrm{B} \alpha$, and are present in the cytosol as an inactive complex in which $\mathrm{I} \kappa \mathrm{B} \alpha$ masks the nuclear localization sequence of $\mathrm{p} 65$ and prevents its nuclear translocation and subsequent DNA binding. ${ }^{3,4}$ The IКB kinase (IKK) complex consists of two catalytic subunits, IKK $\alpha$ (IKK1) and IKK $\beta$ (IKK2), and a regulatory subunit IKK $\gamma$ (NEMO). ${ }^{5,6}$ In the canonical NF- $\kappa B$ signaling pathway, IKK $\beta$ has a major role in phosphorylating IKB at two specific serine residues in the N-terminus (Figure $2 b) .^{7,8}$ Phosphory-

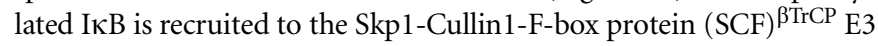
ubiquitin ligase complex that catalyzes the polyubiquitination of

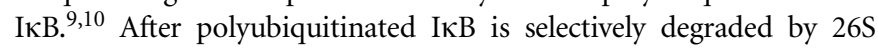
proteasome, the NF- $\mathrm{BB}$ dimers become free and translocate to the nucleus, where they regulate the transcription of many target genes. ${ }^{3,4}$

Tumor necrosis factor- $\alpha$ binds to two different receptors known as TNF receptor 1 (TNF-R1) and TNF receptor 2 (TNF-R2), and triggers a variety of intracellular signaling pathways, one of which leads to
NF- $\kappa \mathrm{B}$ activation (Figure 1). ${ }^{11,12}$ On TNF- $\alpha$ binding, TNF-R1 interacts with the adaptor protein TNF receptor-associated death domain (TRADD) to the cytoplasmic death domain, and this is followed by the recruitment of adaptor proteins receptor-interacting protein 1 (RIP1) and TNF receptor-associated factor 2 (TRAF2) to form complex I at the plasma membrane. ${ }^{13}$ In response to TNF- $\alpha$ stimulation, RIP1 is polyubiquitinated at a specific lysine residue (Lys-377) and subsequently recruits the TGF $\beta$-activated kinase (TAK1) complex and the IKK complex to its polyubiquitin chains. ${ }^{14-16}$ The activation of IKK requires phosphorylation of specific serine residues within the activation loop of the catalytic domain in IKK $\alpha$ and IKK $\beta$ (Figure 2c). ${ }^{5,6}$ Two possible mechanisms are proposed: IKKs phosphorylate each other by trans-autophosphorylation and IKKs are phosphorylated by other upstream kinases, including TAK1. 5,6

After dissociation from the membrane-bound complex, TRADD and RIP1 interact with the adaptor protein Fas-associated death domain (FADD) and the initiator caspase- 8 to form complex II in the cytosol, which mediates the homodimerization and subsequent self-processing of caspase- 8 into its active tetramer (Figure 1). ${ }^{13}$ Active caspase- 8 cleaves various substrates, such as effector caspases and the BH3-only protein Bid, to yield their active forms. Truncated Bid is translocated to mitochondria and induces the release of mitochondrial pro-apoptotic proteins, such as cytochrome $c$, into the cytosol. Cytochrome $c$ collaborates with adaptor protein apoptotic proteaseactivating factor-1 (Apaf-1) to activate initiator caspase- 9 in the apoptosome, allowing for the activation of effector caspases. Active effector caspases mediate the proteolytic cleavage of many cellular proteins and the execution of resultant apoptosis.

Cellular FADD-like IL-1 $\beta$-converting enzyme (FLICE)-inhibitory protein (c-FLIP) is an NF- $\kappa \mathrm{B}$-inducible protein that modulates caspase8 activation, and is a short-lived protein regulated posttranslationally 


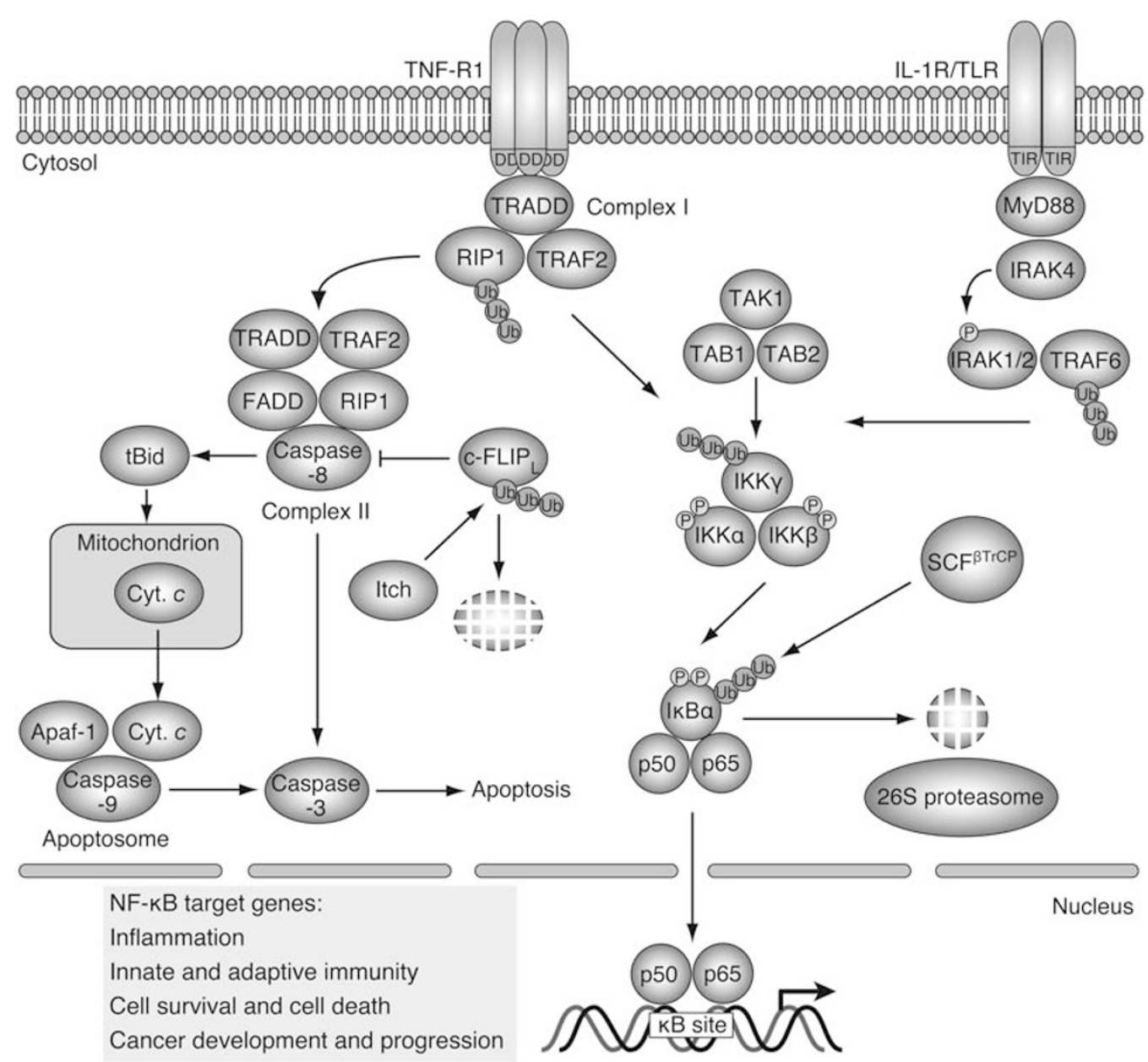

Figure 1 Inflammatory cytokine receptors and their intracellular signaling pathways. On tumor necrosis factor- $\alpha$ (TNF- $\alpha$ ) stimulation, TNF receptor 1 (TNF-R1) recruits TNF receptor-associated death domain (TRADD) to its death domain (DD), and this is followed by the recruitment of receptor-interacting protein 1 (RIP1) and TNF receptor-associated factor 2 (TRAF2). RIP1 is then polyubiquitinated and subsequently recruits the TGF $\beta$-activated kinase (TAK1) complex and the inhibitor of NF-KB (IKB) kinase (IKK) complex to its polyubiquitin chain. Interleukin-1 receptor (IL-1R)/Toll-like receptor (TLR) recruits myeloid differentiation protein 88 (MyD88) to its Toll-IL-1 receptor (TIR) domain, which in turn recruits the IL-1 receptor-associated kinase (IRAK) family of proteins. IRAK4 phosphorylates IRAK1 and IRAK2, which promote the recruitment of TRAF6 and its polyubiquitination. Polyubiquitinated TRAF6 then recruits the IKK complex and the TAK1 complex to its polyubiquitin chains. IKK $\alpha$ and IKK $\beta$ are activated by trans-autophosphorylation or other upstream kinases such as TAK1. The IKK complex phosphorylates N-terminal two serine residues of IKB $\alpha$. Phosphorylated I $\mathrm{B} \alpha$ is polyubiquitinated by Skp1-Cullin1F-box protein (SCF) ${ }^{\beta T C P}$ and selectively degraded by the $26 \mathrm{~S}$ proteasome. The p65/p50 heterodimer becomes free and translocates to the nucleus, where it binds the $\kappa \mathrm{B}$ site and regulates various target genes. In the apoptosis signaling pathway, the complex $I$ is released from the plasma membrane and then interacts with Fas-associated death domain (FADD) and caspase-8 to form complex II. Caspase-8 is activated by dimerization and subsequent self-processing into its active tetramer, which cleaves selective downstream substrates such as Bid and effector caspases. Bid is cleaved into its active form (tBid), which translocates to mitochondria and induces the release of pro-apoptotic proteins such as cytochrome $c$ (Cyt. $c$ ) from mitochondria. Cyt. $c$ collaborates with apoptotic protease-activating factor-1 (Apaf-1) to activate caspase-9 in the apoptosome. Active effector caspases, such as caspase-3, mediate the proteolytic cleavage of many cellular substrates, leading to apoptosis execution. TNF- $\alpha$ does not induce apoptosis in many types of cells by the nuclear factor- $\mathrm{B}$ (NF-KB)-dependent upregulation of c-FLIP (cellular FADD-like IL-1 $\beta$-converting enzyme-inhibitory protein), which prevents the activation of caspase-8. C-FLIP , a long isoform of C-FLIP, is specifically ubiquitinated by Itch and rapidly degraded by the proteasome.

through the ubiquitin-proteasome pathway (Figure 1). ${ }^{17,18}$ The E3 ubiquitin ligase, Itch, specifically ubiquitinates a long isoform of c-FLIP $\left(\mathrm{c}-\right.$ FLIP $\left._{\mathrm{L}}\right)$ and induces its proteasomal degradation. ${ }^{19}$ TNF- $\alpha$ does not induce apoptosis in many types of cells, largely because of its ability to induce NF- $\kappa \mathrm{B}$ activation, and thereby upregulate c-FLIP to levels sufficient to block apoptosis. Protein synthesis inhibitors block the translation of NF- $\kappa B$-inducible proteins, such as c-FLIP, and are thus often used to sensitize cells to undergo TNF- $\alpha$-induced apoptosis. ${ }^{12,17}$

Interleukin-1 can also induce NF- $\kappa \mathrm{B}$ activation. The IL-1 receptor (IL-1R) and Toll-like receptors (TLRs) possess a cytoplasmic Toll-IL-1 receptor (TIR) domain. On ligand binding, IL-1R and TLRs trigger the recruitment of the adaptor protein myeloid differentiation protein 88 (MyD88), which in turn recruits the IL-1 receptor-associated kinase (IRAK) family members to their TIR domain (Figure 1). ${ }^{9,10,20}$ IRAK4 recruited to the receptor complex phosphorylates and activates IRAK1 and IRAK2, and these molecules in turn promote the recruitment of the RING-domain protein TRAF6 and its oligomer formation. ${ }^{9,10}$ TRAF6 oligomerization activates its ubiquitin ligase, leading to the polyubiquitination of target proteins, including TRAF6 itself. ${ }^{9,10}$ Polyubiquitinated TRAF6 recruits the IKK complex and the TAK1 complex to its polyubiquitin chains, leading to the activation of IKK. ${ }^{9,10}$ 

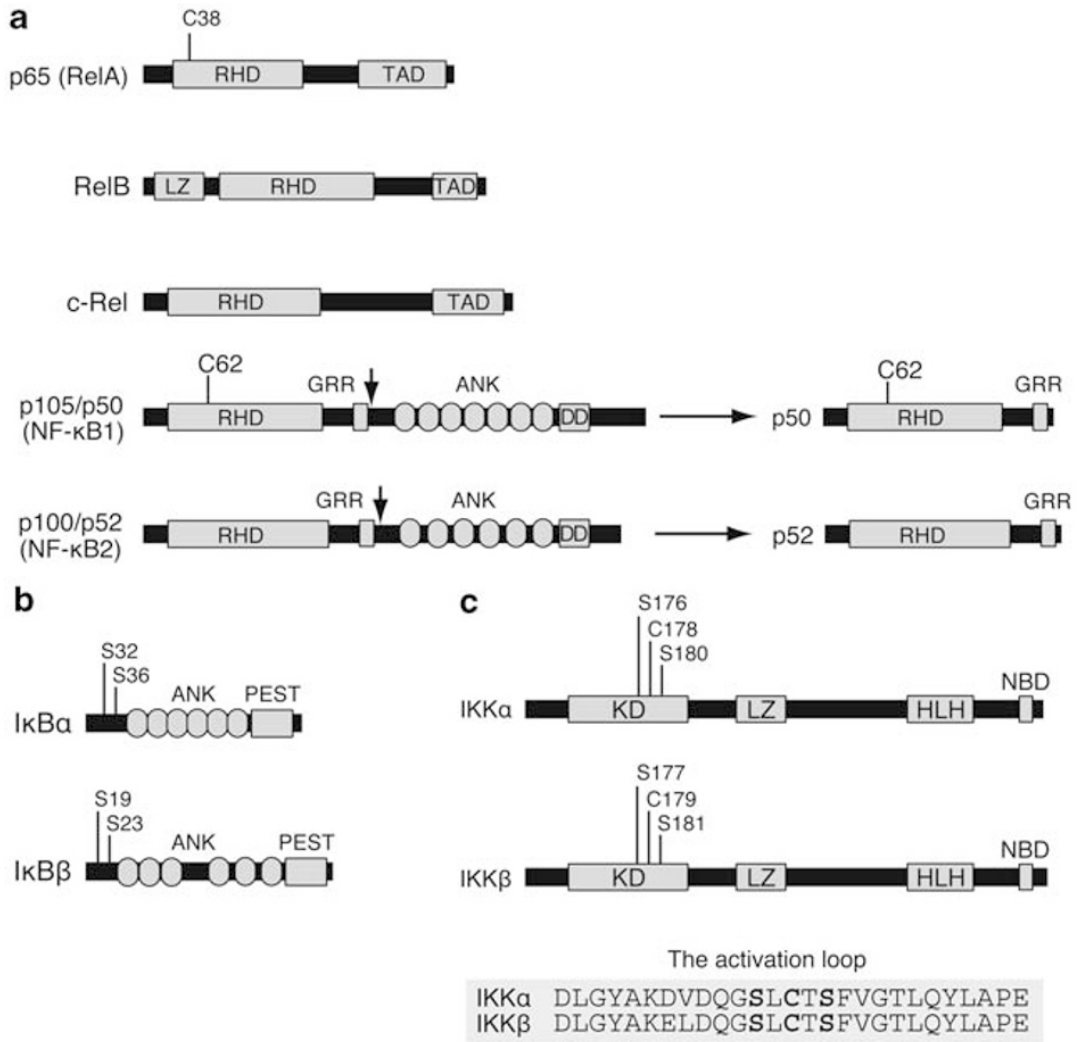

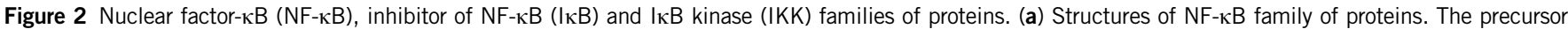
proteins p105 and p100 are cleaved into p50 and p52 by the proteasome, as indicated by arrows. (b) Structures of $1 \kappa B \alpha$ and $1 \kappa B \beta$. N-terminal two serine residues phosphorylated by IKK are shown. (c) Structures of IKK $\alpha$ and IKK $\beta$. Two serine residues phosphorylated and a critical cysteine residue in the activation loop within the kinase domain are shown. ANK, ankyrin repeat; DD, death domain; GRR, glycine-rich region; HLH, helix-loop-helix domain; KD, kinase domain; LZ, leucine zipper domain; NBD, NEMO-binding domain; RHD, Rel homology domain; and TAD, transactivation domain.

It has recently become clear that the NF- $\kappa \mathrm{B}$ signaling pathway has a central role not only in inflammation but also in cancer development. ${ }^{1,2}$ NF- $\kappa B$ inhibitors are most likely to be of great use as therapeutic agents for inflammatory diseases and cancer, and as bioprobes for the characterization of intracellular biological response and cell function. In the past decade, a number of structurally diverse small molecules have been identified that block the NF- $\kappa B$ signaling pathway. This review describes recent progress in the identification and biological properties of natural and synthetic small molecules targeting the NF- $\mathrm{KB}$ signaling pathway.

\section{SYNTHETIC IKK INHIBITORS}

The IKK complex of IKK $\alpha$ and IKK $\beta$ directly phosphorylates IKB $\alpha$ at the two N-terminal serine residues (Ser-32 and Ser-36) (Figure 2b)., ${ }^{7,8}$ IKK $\beta$ has a major role in $I \kappa B \alpha$ phosphorylation in the NF- $\kappa B$ signaling pathway in response to pro-inflammatory cytokines and thus, its inhibition represents a potentially attractive way to treat inflammatory diseases. IKK-i ${ }^{21}$ (also known as IKKE ${ }^{22}$ ) and TANKbinding kinase 1 (TBK1)/NF- $\kappa \mathrm{B}$-inducing kinase/TRAF2-associated kinase are IKK-related kinases that are activated in response to various stimuli. The substrate specificity of IKK-i and TBK1 is distinct from that of IKK $\alpha$ and IKK $\beta .^{23}$ Small molecules that directly inhibit IKK $\alpha$ or IKK $\beta$ have been developed by many research groups (Table 1 ). Specific IKK $\beta$ inhibitors have been further employed to block NF- $\kappa B$ activation in various cell types and animal models.

Many IKK $\beta$ inhibitors have been designed and synthesized from lead compounds identified by high-throughput screening based on an in vitro kinase assay. 5-Bromo-6-methoxy- $\beta$-carboline, a methylated natural product derivative, was initially obtained as a lead compound that non-specifically inhibits endogenous IKK and other kinases, and further chemical optimization has led to the identification of $N$-(6-chloro- $9 H$ - $\beta$-carbolin-8-yl)nicotinamide (PS-1145) as a selective IKK $\beta$ inhibitor and $N$-(6-chloro-7-methoxy- $9 H$ - $\beta$-carbolin-8-yl)-2methylnicotinamide (ML120B) as a more potent, reversible and ATP-competitive IKK $\beta$ inhibitor. ${ }^{24-27}$ 4-Amino-2,3'-bithiophene-5carboxamide (SC-514), an ATP-competitive IKK $\beta$ inhibitor, has an IC $_{50}$ value $>10 \mu \mathrm{M}$, but has little or no inhibitory effect on other kinases. ${ }^{28}$ On the basis of the thiophenecarboxamide structure, more potent thiophenecarboxamide-type IKK $\beta$ inhibitors, such as 2((aminocarbonyl)amino)-5-(4-fluorophenyl)-3-thiophenecarboxamide (TPCA-1), as well as benzothieno(3,2-b)furan derivatives as novel IKK $\beta$ inhibitors, have been developed independently by four individual groups. ${ }^{29-32}$ The identification of a 2-amino-3-cyano-4-aryl-6(2-hydroxyphenyl)pyridine analog as a lead compound by highthroughput screening assay and subsequent chemical optimization have led to the identification of 2-amino-6-(2-(cyclopropylmethoxy)6-hydroxyphenyl)-4-piperadin-4-yl nicotinonitrile (ACHP) as a potent and selective IKK $\beta$ inhibitor. ${ }^{33-35}$ In the course of in vitro screening of a series of anilinopyrimidine derivatives and ATP competitors for their inhibitory effects on a constitutively active version of IKK $\beta$ in which two serine residues within the activation loop of the catalytic domain are replaced with glutamic acids, AS602868 was identified to be a potent, reversible and ATP-competitive IKK $\beta$ inhibitor, ${ }^{36,37}$ and has been thus far used in various cell 
Table 1 Profiles of synthetic IKK inhibitors

\begin{tabular}{|c|c|c|c|c|c|c|}
\hline \multirow[b]{2}{*}{ Compound } & \multicolumn{4}{|c|}{$1 C_{50}(\mathrm{nM})$} & \multirow[b]{2}{*}{ Company } & \multirow[b]{2}{*}{ Reference } \\
\hline & $I K K \alpha$ & $I K K \beta$ & $I K K-i$ & $I K K^{a}$ & & \\
\hline AS602868 & 14000 & 62 & & & Merck Serono & Frelin et al. ${ }^{36} ;$ Heckmann et al. ${ }^{37}$ \\
\hline 2-Benzamido-pyrimidine $(\mathbf{1 6})^{\mathrm{b}}$ & 200 & 40 & & 70 & Novartis & Waelchli et al. ${ }^{44}$ \\
\hline BMS-345541 & 4000 & 300 & $>100000$ & & Bristo-Myers Squibb & Burke et al. ${ }^{38}$; Beaulieu et al. ${ }^{39}$ \\
\hline PF-184 & & 37 & & & Pfizer & Sommers et al. 50 \\
\hline PHA-408 & 14100 & 40 & $>200000$ & & Pfizer & Mbalaviele et al. ${ }^{49}$; Sommers et al. ${ }^{50}$ \\
\hline PS-1145 & & & & 100 & Millennium Pharmaceuticals & Hideshima et al..24; Castro et al. ${ }^{25}$ \\
\hline S1627 & & & & 10 & Sanofi-aventis & Tegeder et al. ${ }^{43}$ \\
\hline SC-514 & $>200000$ & 11200 & $>200000$ & 6100 & Pfizer & Kishore et al. ${ }^{28}$ \\
\hline TPCA-1 & 400 & 17.9 & & & GlaxoSmithKline & Podolin et al. ${ }^{31}$ \\
\hline
\end{tabular}

Abbreviations: ACHP, 2-amino-6-(2-(cyclopropylmethoxy)-6-hydroxyphenyl)-4-piperadin-4-yl nicotinonitrile; BMS-345541, 4-(2'-aminoethyl)amino-1,8-dimethylimidazo(1,2-a)quinoxaline; IKK, inhibitor of nuclear factor-kB kinase; IMD-0354, $N$-(3,5-bis-trifluoromethyl-phenyl)-5-chloro-2-hydroxybenzamide; ML120B, $N$-(6-chloro-7-methoxy-9H- $\beta$-carbolin-8-yl)-2-methylnicotinamide; PF-184, 8-(2-(3,4-bis(hydroxymethyl)-3,4-dimethylpyrrolidin-1-yl)-5-chloroisonicotinamido)-1-(4-fluorophenyl)-4,5-dihydro-1 H-benzo-[g]indazole-3-carboxamide; PHA-408, 8-(5-chloro-2-(4-methylpiperazin1-yl)isonicotinamido)-1-(4-fluorophenyl)-4,5-dihydro- $1 \mathrm{H}$-benzo[g]indazole-3-carboxamide; PS-1145, $\mathrm{N}$-(6-chloro-9H- $\beta$-carbolin-8-yl)nicotinamide; SC-514, 4-amino-2,3'-bithiophene-5-carboxamide; TPCA-1, 2-((aminocarbonyl)amino)-5-(4-fluorophenyl)-3-thiophenecarboxamide.

alKK complex purified from cells was used in the in vitro kinase assay.

bThe compound number in the reference is given in bold.

types and animal models. In addition to the ATP-competitive types of IKK $\beta$ inhibitors described above, 4-(2'-aminoethyl)amino-1,8dimethylimidazo(1,2-a)quinoxaline (BMS-345541) was identified as a highly selective IKK $\beta$ inhibitor that binds to an allosteric binding site, by means of an in vitro kinase assay. ${ }^{38}$ Further structure-activity relationship studies of BMS-345541 as a structural lead have recently revealed that its tetracycline analogs and imidazo $(1,2-a)$ thieno(3,2-e) pyrazines are more potent IKK $\beta$ inhibitors. ${ }^{39,40}$ As a different approach to the development of IKK $\beta$ inhibitors, the molecular structure of $\mathrm{N}$-(3,5-bis-trifluoromethyl-phenyl)-5-chloro-2-hydroxybenzamide (IMD-0354) was designed by analyzing the binding mode of aspirin to IKK $\beta$ after the construction of the three-dimensional structure of a kinase domain of IKK $\beta$ by homology modeling with protein kinase $\mathrm{A}$ as a template, and the estimation of the structure of active IKK $\beta$ by referring to a model of IKK regulation. ${ }^{41,42}$ The phase I clinical trial of topical formulation of IMD-0354 for treatment of atopic dermatitis has been successfully completed. Other synthetic IKK inhibitors, including S1627, ${ }^{43}$ 2-benzamido-pyrimidines, ${ }^{44}$ 2-amino-3,5-diarylbenzamides, ${ }^{45,46}$ 6-aryl-7-alkoxyisoquinolines, ${ }^{47}$ 4-phenyl-7-azaindoles, ${ }^{48}$ PHA-408 $8^{49,50}$ and PF- $184,{ }^{50}$ have been reported.

\section{THIOL-REACTIVE IKK INHIBITORS}

IKK $\alpha$ and IKK $\beta$ contain serine residues within the activation loop of the catalytic domain (Ser-176 and Ser-180 in IKK $\alpha$, and Ser-177 and Ser-181 in IKK $\beta$ ), and their phosphorylation is required to induce kinase activity (Figure 2c). ${ }^{51,52} \mathrm{IKK} \alpha$ and IKK $\beta$ also contain cysteine at positions 178 and 179 within their activation loop, respectively (Figure 2c). ${ }^{53,54}$ Indeed, it has been shown that Cys-179 of IKK $\beta$ is critical for enzyme activation by promoting the phosphorylation of serines in the activation loop. ${ }^{55}$ The IKK $\beta$ mutant in which Cys- 179 is replaced with alanine exhibited reduced kinase activity in response to physiological stimuli, whereas it exerted enzymatic activity at levels similar to wild-type IKK $\beta$ when co-expressed with mitogen-activated protein (MAP) kinase kinase kinase, such as NF- $\kappa B$-inducing kinase $^{53-55}$ The difference in sensitivity between wild-type IKK $\beta$

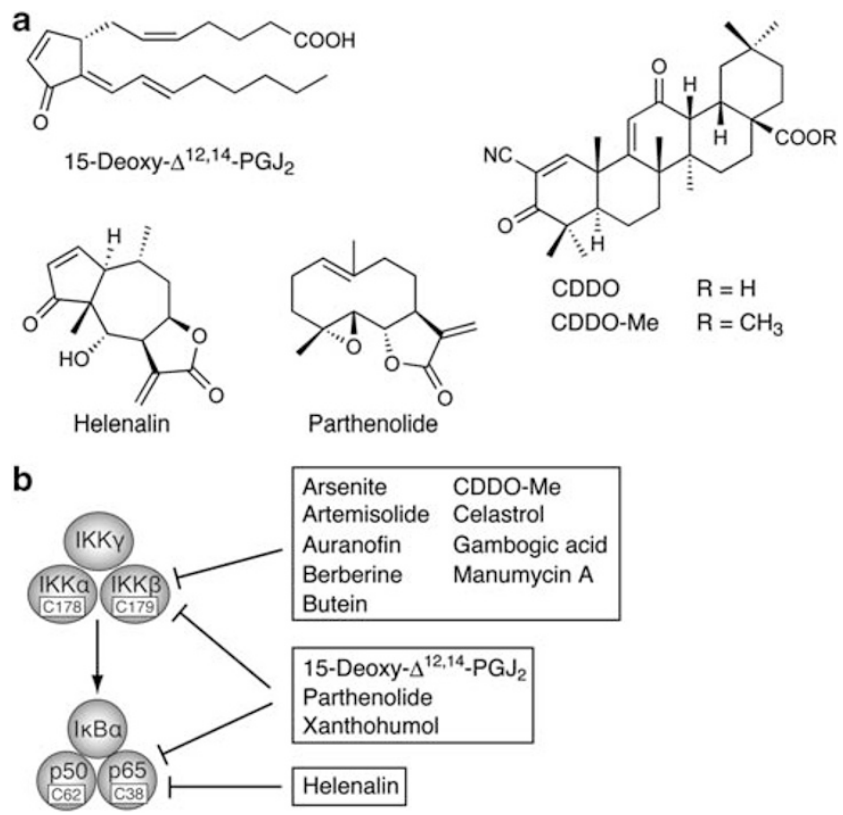

Figure 3 Structures and molecular targets of natural and synthetic compounds containing $\alpha, \beta$-unsaturated carbonyl moieties. (a) Structures. (b) Target proteins in the nuclear factor- $\mathrm{B}(\mathrm{NF}-\kappa \mathrm{B})$ signaling pathway are shown.

and its mutant IKK $\beta$ (C179A) in cell culture or in their purified forms clearly revealed that a large number of small molecules directly inhibit IKK $\beta$ activity by the modification of Cys- 179 .

Prostaglandin $\mathrm{J}_{2}\left(\mathrm{PGJ}_{2}\right)$ and its metabolites, such as 15-deoxy$\Delta^{12,14}-\mathrm{PGJ}_{2}$ (Figure $3 \mathrm{a}$ ), are naturally occurring metabolites of prostaglandin $\mathrm{D}_{2}$. 15 -Deoxy- $\Delta^{12,14}-\mathrm{PGJ}_{2}$ inhibits the NF- $\kappa \mathrm{B}$ signaling pathway by inhibiting IKK $\beta$ activity. ${ }^{54,56}$ Synthetic triterpenoids, 2-cyano-3,12-dioxooleana-1,9-dien-28-oic acid methyl ester (CDDO$\mathrm{Me}$, as shown in Figure 3a) and 1-(2-cyano-3,12-dioxooleana-1,9dien-28-oyl)imidazole (CDDO-Im), also block NF- $\kappa$ B activation 
through the direct inhibition of IKK $\beta .^{57,58}$ The C179A mutation confers IKK $\beta$ resistance to 15 -deoxy- $\Delta^{12,14}-\mathrm{PGJ}_{2}, \mathrm{CDDO}-\mathrm{Me}$ and CDDO-Im. ${ }^{54,57,58}$ This is consistent with the fact that 15-deoxy$\Delta^{12,14}-\mathrm{PGJ}_{2}, \mathrm{CDDO}-\mathrm{Me}$ and CDDO-Im contain an $\alpha, \beta$-unsaturated carbonyl moiety that is known to form reversible adducts with reactive thiol groups. In the NF- $\kappa \mathrm{B}$ signaling pathway, it seems that Cys-179 of IKK $\beta$ is highly reactive and thus targeted by many other compounds, including arsenite, ${ }^{53}$ auranofin, ${ }^{59}$ manumycin $\mathrm{A},{ }^{60}$ celastrol, ${ }^{61}$ butein, ${ }^{62}$ berberine, ${ }^{63}$ xanthohumol ${ }^{64}$ and gambogic acid (Figure $3 \mathrm{~b}$ ). ${ }^{65}$

\section{SESQUITERPENE LACTONES AND RELATED COMPOUNDS}

Sesquiterpene lactones are a large group of secondary metabolites of many medicinal plants. Sesquiterpene lactones often possess $\alpha$, $\beta$ unsaturated carbonyl moieties, such as $\alpha$-methylene- $\gamma$-lactones. These functional groups are known to react with cysteine thiol groups in the Michael-type addition. ${ }^{66}$ It has been reported that many sesquiterpene lactones exert anti-inflammatory activity by preventing NF- $\kappa B$ activation. Helenalin (Figure $3 a$ ), a sesquiterpene lactone that possesses an $\alpha$-methylene- $\gamma$-lactone moiety, was initially isolated from flower head extract and found to inhibit NF- $\kappa \mathrm{B}$ activation in response to various stimuli. ${ }^{67}$ It has been shown that helenalin does not inhibit I $\kappa \mathrm{B}$ degradation or NF- $\kappa \mathrm{B}$ nuclear translocation, but rather the DNAbinding activity of NF- $\kappa \mathrm{B}$ in the NF- $\kappa \mathrm{B}$ signaling pathway. ${ }^{6}$ Helenalin inhibits the NF- $\kappa B$-binding activity of wild-type p65, but not that of its mutant p65 (C38S), whereas 11 $\alpha, 13$-dihydrohelenalin acetate, which is devoid of the $\alpha$-methylene- $\gamma$-lactone moiety, has a much weaker inhibitory effect. ${ }^{69}$ Thus, as a major molecular target in the NF- $\kappa \mathrm{B}$ signaling pathway, helenalin can selectively alkylate the p65 subunit of NF- $\kappa \mathrm{B}$ at Cys-38, thereby interfering with its DNA-binding activity (Figure $3 \mathrm{~b}$ ).

Parthenolide (Figure 3a) is a sesquiterpene lactone that contains an $\alpha$-methylene- $\gamma$-lactone moiety. It was identified as an NF- $\kappa \mathrm{B}$ inhibitor in the leaf extracts of Mexican Indian medicinal plants. ${ }^{70}$ Parthenolide inhibits a common step in the activation of NF- $\kappa \mathrm{B}$ in response to many stimuli as well as in various cell types. ${ }^{69,71,72}$ It has been shown that parthenolide inhibits constitutively active IKK $\beta$ (S177E/S181E) but not IKK $\beta$ (C179A), which shows that parthenolide binds to IKK $\beta$ and inhibits its kinase activity by the direct modification of Cys-179. ${ }^{73}$ This is in agreement with the findings that parthenolide prevents IKK activation and subsequent $\mathrm{I} \kappa \mathrm{B} \alpha$ phosphorylation and degradation. ${ }^{71,72}$ However, it has also been reported that parthenolide does not effectively inhibit IKK activation, but rather inhibits the DNA binding of NF- $\kappa$ B in different cell systems. ${ }^{69,74}$ Parthenolide has been found to inhibit the DNA-binding activity of wild-type p65, but not that of p65 (C38S) ${ }^{69,74}$ Collectively, it seems most likely that both Cys-38 of p65 and Cys- 179 of IKK $\beta$ are target residues of parthenolide, with Cys-38 of p65 being more preferentially alkylated under certain experimental settings (Figure $3 \mathrm{~b}$ ). Similarly, it has been shown that 15 -deoxy- $\Delta^{12,14}$ $\mathrm{PGJ}_{2}$ targets both Cys-179 of IKK $\beta$ and Cys-38 of p65. ${ }^{56}$ As one of the sesquiterpene lactones that contain an $\alpha$-methylene- $\gamma$-lactone moiety, artemisolide has been reported to inhibit IKK $\beta$ activity by targeting its Cys- $179 .^{75}$

Intercellular adhesion molecule-1 (ICAM-1; CD54) is a cell-surface glycoprotein that belongs to the immunoglobulin superfamily. It serves as a ligand for lymphocyte-function-associated antigen-1 (LFA-1; CD11a/CD18) and Mac-1 (CD11b/CD18). ICAM-1 is expressed at low levels on many types of cells and its expression is predominantly upregulated at the transcriptional level by NF- $\kappa \mathrm{B}$ in response to pro-inflammatory cytokines. A series of guaianolide and eudesmane types of sesquiterpenes have been synthesized or isolated from plant extracts, and investigated for their ability to inhibit surface
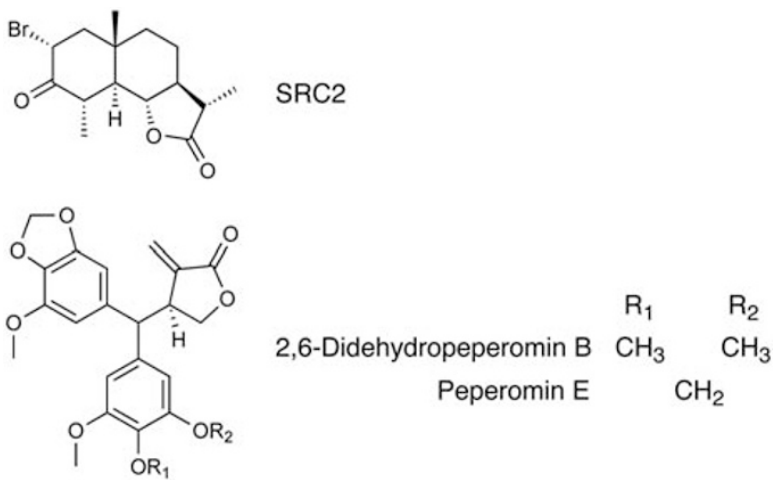

Figure 4 Structures of SRC2 ((11S)-2 $\alpha$-bromo-3-oxoeudesmano-13,6 $\alpha$ lactone) and peperomins.

ICAM-1 expression in human lung carcinoma A549 cells stimulated with IL- 1 or TNF- $\alpha$. Guaianolide derivatives possessing $\alpha$-methylene$\gamma$-lactone moieties, such as dehydrocostus lactone, exert inhibitory effects at $\mathrm{IC}_{50}$ values lower than $10 \mu \mathrm{M}$, whereas other $\alpha$-methyl- $\gamma$ lactone derivatives show much weaker inhibitory effects. ${ }^{76-78}$ These findings clearly show that an $\alpha$-methylene- $\gamma$-lactone moiety is crucial to inhibit the induction of ICAM-1 expression. This notion is consistent with the structure-activity relationship study of the effect of sesquiterpene lactones on NF- $\kappa B$-binding activity in TNF- $\alpha$-stimulated cells, which shows that various guaianolides and eudesmanes containing $\alpha$-methylene- $\gamma$-lactones manifest inhibitory effects. ${ }^{79}$ We have also synthesized (11S)-2 $\alpha$-bromo-3-oxoeudesmano-13,6 $\alpha$ lactone (SRC2, as shown in Figure 4) from the starting material $L-\alpha-$ santonin. ${ }^{80}$ SRC2 is devoid of the $\alpha$-methylene- $\gamma$-lactone moiety, but has a bromoketone structure at the A-ring. SRC2 inhibits the induction of cell-surface ICAM-1 expression in response to IL-1 stimulation by blocking the signaling pathway upstream of IКB degradation. ${ }^{80}$ Investigations of the molecular mechanism by which SRC2 inhibits $\mathrm{NF}-\kappa \mathrm{B}$ activation are in progress.

Peperomins are secolignans isolated from the Peperomia family of plants. Recently, we have reported that several secolignans isolated from the extract of Peperomia dindygulensis inhibit cell-surface ICAM1 expression induced by pro-inflammatory cytokines. ${ }^{81}$ However, except for their anti-inflammatory activity, ${ }^{81}$ multidrug resistance reversal activity ${ }^{81}$ and anticancer activity, ${ }^{81,82}$ the biological activities of peperomins are little understood. Peperomin E and 2,6-didehydropeperomin B (Figure 4) are structural analogs of peperomin A and peperomin B in which the $\alpha$-methylene- $\gamma$-lactone groups are replaced with $\alpha$-methyl- $\gamma$-lactone groups, respectively. We have recently shown that peperomin $\mathrm{E}$ and 2,6-didehydropeperomin $\mathrm{B}$, but not peperomin A or peperomin $B$, inhibit $I \kappa B \alpha$ degradation induced by TNF- $\alpha$ or IL-1 in A549 cells. ${ }^{83}$ In the NF- $\kappa$ B signaling pathway, peperomin $\mathrm{E}$ and 2,6-didehydropeperomin B are able to block TNF- $\alpha$-induced IKK activation. ${ }^{83}$ However, in contrast to $\alpha$-methylene- $\gamma$-lactone types of sesquiterpene lactones, such as parthenolide or artemisolide, peperomin $\mathrm{E}$ and 2,6-didehydropeperomin B do not inhibit IKK $\beta$ activity directly. ${ }^{83}$ Therefore, peperomin $\mathrm{E}$ and 2,6-didehydropeperomin $\mathrm{B}$ do not primarily block IKK $\beta$ activity by the modification of Cys-179, but are likely to target other protein(s) required for IKK activation.

\section{EPOXYQUINOIDS}

Natural and synthetic epoxyquinoids, such as cycloepoxydon, ${ }^{84,85}$ dehydroxymethylepoxyquinomicin (DHMEQ), ${ }^{86}$ epoxyquinol $\mathrm{A},{ }^{87}$ 
epoxyquinol $\mathrm{B},{ }^{88}$ epoxyquinone $\mathrm{A}$ monomer, ${ }^{87}$ jesterone dimer, ${ }^{89,90}$ manumycin $\mathrm{A}^{60}$ and panepoxydone, ${ }^{91}$ have been reported to inhibit $\mathrm{NF}-\kappa \mathrm{B}$ activation. Epoxyquinoids contain the epoxide structure that is known to react with nucleophiles, such as cysteine thiol groups. Given that the reactivity of epoxyquinoids to proteins is similar to that of compounds containing $\alpha, \beta$-unsaturated carbonyl moieties, it is speculated that epoxyquinoids selectively target critical cysteine residues of IKK $\beta$ and $\mathrm{p} 65$ in the NF- $\kappa \mathrm{B}$ signaling pathway. With regard to some epoxyquinoids, novel molecular mechanisms involved in the suppression of NF- $\kappa \mathrm{B}$ activation have been revealed.

Epoxyquinols A and B (Figure 5a), which are naturally occurring pentaketide dimers, have been isolated from fungal metabolites and found to possess potent antiangiogenic activity. ${ }^{92,93}$ It has also been shown that both epoxyquinols A and B block TNF- $\alpha$-induced NF- $\kappa B$ activation. ${ }^{87,88}$ Compared with epoxyquinol $\mathrm{A}$, its structural derivative, epoxyquinone A monomer (Figure $5 \mathrm{a}$ ), is a potent inhibitor of TNF- $\alpha$-induced NF- $\kappa B$ activation. ${ }^{87}$ Similar to sesquiterpene lactones, epoxyquinone A monomer inhibits IKK $\beta$ and p65 by targeting Cys-179 and Cys-38, respectively (Figure 5b). ${ }^{94}$ Jesterone dimer (Figure 5a), which was reported to exert 10 - to 100 -fold greater antitumor activity than jesterone, has been shown to block TNF- $\alpha$ induced IKK activation. ${ }^{89,90}$ Indeed, jesterone dimer converts constitutively active IKK $\beta$ into stable higher molecular mass forms, irrespective of its Cys-179 mutation (Figure $5 \mathrm{~b}) .{ }^{90}$ It has also been shown that epoxyquinol $\mathrm{B}$ is able to bind covalently to cysteine residues of several proteins and to crosslink proteins through the cysteine residues by opening its epoxide ring. ${ }^{88,95}$ In the NF- $\kappa B$ signaling pathway upstream of IKK activation, epoxyquinol B does not block TNF- $\alpha$ induced RIP1 polyubiquitination; rather, it inhibits TAK1 phosphorylation. ${ }^{88}$ As a molecular target, TAK1 has been identified to be crosslinked to high molecular weight complexes by itself or to other proteins by epoxyquinol B (Figure $5 \mathrm{~b}$ ). ${ }^{88}$ Therefore, it seems likely that epoxyquinoid dimers, such as epoxyquinol B, preferentially crosslink TAK1 or IKK $\beta$, whereas epoxyquinoid monomers may target critical cysteine residues of IKK $\beta$ or p65. As a direct TAK1 inhibitor with a different mode of action, 5Z-7-oxozeaenol has been identified to be a selective and ATP-competitive inhibitor with an $\mathrm{IC}_{50}$ value of $8 \mathrm{~nm}$, in a screening of 90 compounds (including 59 compounds that have been reported to inhibit protein kinases) with an in vitro kinase assay system using purified TAK1 and TAB1 proteins expressed in insect cells. ${ }^{96}$ a

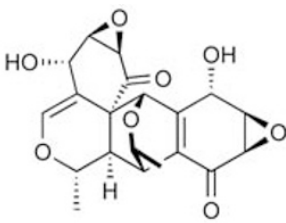

Epoxyquinol A

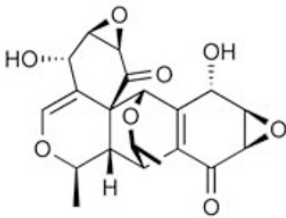

Epoxyquinol B<smiles>C/C=C/C1=C(CO)C(=O)C2OC2C1=O</smiles>

Epoxyquinone A monomer<smiles>O=C(NC1=CC(=O)C2OC2C1O)c1ccccc1O</smiles>

$(-)-D H M E Q$

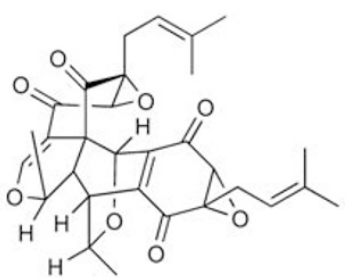

Jesterone dimer<smiles>[R]C1=C(CO)[C@@H](O)C2OC2C1=O</smiles>

$\mathrm{ECH} \mathrm{R}=-\mathrm{CH}=\mathrm{CH}-\mathrm{CH}_{3}$ (E-form)

RKTS-33 $\mathrm{R}=\mathrm{H}$

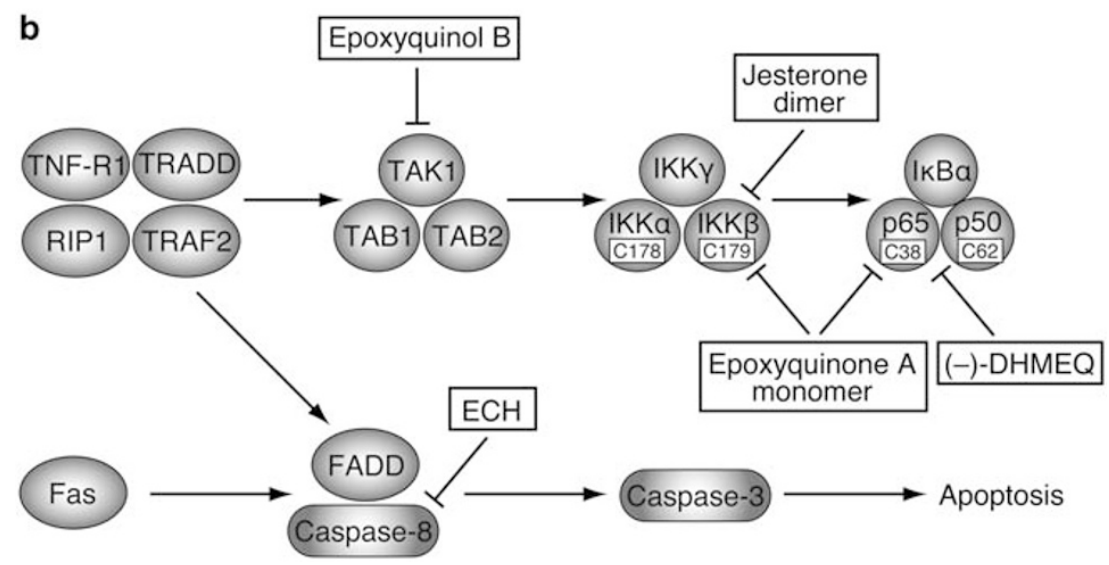

Figure 5 Structures of epoxyquinoids and their molecular targets. (a) Structures of epoxyquinoids. (b) Target proteins of epoxyquinoids in the tumor necrosis factor receptor 1 (TNF-R1) and Fas signaling pathways are shown. On TNF- $\alpha$ stimulation, TNF receptor 1 (TNF-R1) recruits adaptor proteins (TNF receptorassociated death domain (TRADD), receptor-interacting protein 1 (RIP1) and TNF receptor-associated factor 2 (TRAF2)), which subsequently activates the inhibitor of nuclear factor- $\mathrm{BB}$ kinase (IKK) complex (IKK $\alpha$, IKK $\beta$ and IKK $\gamma$ ) through the TGF $\beta$-activated kinase (TAK1) complex (TAK1, TAB1 and TAB2). On Fas ligand stimulation, Fas recruits FADD (Fas-associated death domain) and caspase-8. Caspase- 8 is activated by self-processing and thereby cleaves specific substrates such as caspase-3, leading to apoptosis execution. 
(-)-DHMEQ (Figure 5a) has been designed as an NF- $\kappa \mathrm{B}$ inhibitor on the basis of the epoxyquinomicin $\mathrm{C}$ structure. ${ }^{86}$ It has been shown that (-)-DHMEQ exerts anti-inflammatory activity in various in vivo models. At the cell level, (-)-DHMEQ inhibits TNF- $\alpha$-induced nuclear translocation of NF- $\kappa \mathrm{B}$ and subsequent binding to DNA, whereas it does not inhibit TNF- $\alpha$-induced I $\mathrm{B}$ phosphorylation and degradation. ${ }^{97}$ Thus, unlike other epoxyquinoids, (-)-DHMEQ selectively inhibits the nuclear translocation of NF- $\kappa \mathrm{B}$ in response to various stimuli. It has been recently reported that (-)-DHMEQ covalently binds specific cysteine residues of Rel family proteins located closed to the DNA-binding sites (Cys-38 of p65, Cys-144 of Rel B, Cys-27 of c-Rel and Cys-62 of p50) (Figure 5b)..$^{98}(-)$-DHMEQ thereby blocks the DNA-binding activity of wild-type, but not mutated (Cys to Ser), Rel family proteins in their purified forms. ${ }^{98}$

As for the bioactive epoxyquinoids, we have shown that $(2 R, 3 R$, $4 S)$-2,3-epoxy-4-hydroxy-5-hydroxymethyl-6-(1E)-propenyl-cyclohex5-en-1-one (ECH, as shown in Figure 5a) and its structural derivatives specifically inhibit Fas-mediated apoptosis. ${ }^{99,100}$ Fas is a cell-surface receptor belonging to the TNF receptor superfamily and has a cytoplasmic death domain essential for the induction of apoptosis in a FADD- and caspase-8-dependent manner. ${ }^{11} \mathrm{ECH}$ specifically inhibits the activation of caspase-8, but not its recruitment to the deathinducing signaling complex (DISC) in Fas ligand (FasL)-stimulated cells, thereby preventing caspase-8-dependent apoptosis. ${ }^{99}$ Although $\mathrm{ECH}$ is the oxidized form of the epoxyquinone A monomer, it does not seem to inhibit IKK $\beta$ activity, as TNF- $\alpha$-induced IKB $\alpha$ degradation still proceeds in the presence of $\mathrm{ECH} .{ }^{99}$ As a selective target in the Fas signaling pathway, ECH binds covalently to caspase-8, as revealed by an immunoprecipitation study using biotinylated ECH. ${ }^{99}$ Thus, ECH is most likely to inactivate caspase- 8 through the modification of a cysteine residue critical for its catalytic activity (Figure 5b). This notion is supported by our finding that the mycotoxin penicillic acid directly binds to a critical cysteine residue within the active center in the catalytic domain of caspase-8 (Figure 6) ${ }^{101}$ In much the same manner as $\mathrm{ECH}$, penicillic acid prevents the activation of caspase- 8 , but not its recruitment to DISC in response to FasL. ${ }^{101} \mathrm{ECH}$ prevents caspase-8dependent apoptosis induced by death receptors (Fas and TNF-R1), but not apoptosis induced by staurosporine, MG-132, C2-ceramide or UV irradiation. ${ }^{99}$ Therefore, unlike other epoxyquinoids, ECH does not seem to be an NF- $\kappa$ B inhibitor, but a specific inhibitor of caspase-8. The molecular mechanism by which epoxyquinoids recognize specific cysteine residues in target proteins is currently unclear and should be clarified to develop highly selective inhibitors.

Cytotoxic T lymphocytes (CTLs) and natural killer cells eliminate target cells, such as tumor and virus-infected cells, by inducing apoptosis through two distinct killing pathways that are dependent on perforin/granzyme B and FasL. We have shown that ECH and its close structural analog, RKTS-33 (Figure 5a), specifically prevent Fas-ligand-dependent apoptosis in CTL-mediated cytotoxicity, whereas these agents barely affect perforin/granzyme B-dependent CTL-mediated cytotoxicity. ${ }^{102,103}$ We have previously shown that the perforin/granzyme B-dependent CTL-mediated killing pathway is selectively blocked by concanamycin A, an 18-membered macrolide that specifically inhibits vacuolar-type $\mathrm{H}^{+}$-ATPase. ${ }^{104}$ Therefore, in combination with concanamycin $\mathrm{A}, \mathrm{ECH}$ can be used as a specific inhibitor of FasL-dependent killing pathway to evaluate the contribution of two distinct killing pathways in various CTL-target settings.

\section{CARDENOLIDE GLYCOSIDES}

Cardiac glycosides, such as ouabain (Figure 7a), comprise a large number of naturally occurring compounds and consist of three

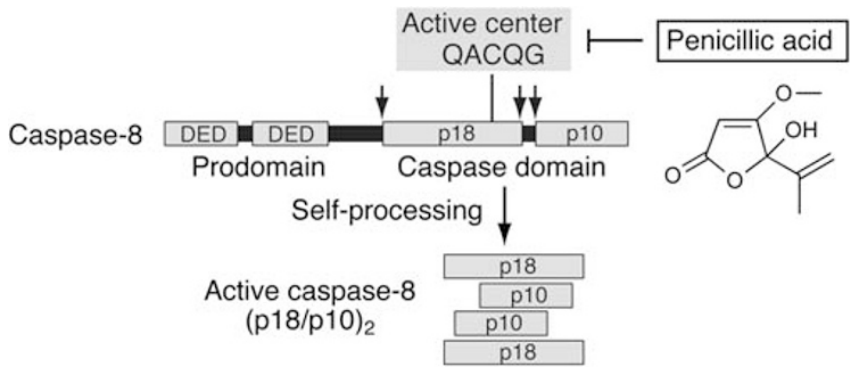

Figure 6 Structure of caspase- 8 and its mechanism of activation. Caspase-8 is composed of two death effector domains (DED) as a prodomain and a caspase domain for its catalytic activity. The active center (QACQG) is located in the p18 subunit of the caspase domain. On dimerization, caspase- 8 is cleaved into $\mathrm{p} 18$ and p10 subunits by self-processing, as indicated by arrows, and converted into the active tetramer (p18/p10) which processes specific downstream substrates. Penicillic acid covalently binds to a cysteine residue in the active center and thereby prevents its enzymatic activity. The structure of penicillic acid is shown.

distinct structural motifs: a steroid core, a sugar moiety and a lactone moiety. Cardiac glycosides are further divided into cardenolides and bufadienolides having a five-membered butyrolactone ring and a sixmembered unsaturated pyrone ring, respectively. Cardiac glycosides are defined as inhibitors of $\mathrm{Na}^{+} / \mathrm{K}^{+}$-ATPase, and used as drugs for treating heart failure and as anticancer drugs in clinical trials. ${ }^{105}$ $\mathrm{Na}^{+} / \mathrm{K}^{+}$-ATPase is composed of a catalytic $\alpha$-subunit and a regulatory $\beta$-subunit. It serves as a primary active transporter that is able to pump $\mathrm{Na}^{+}$out and $\mathrm{K}^{+}$in through hydrolysis of ATP, and maintains transmembrane $\mathrm{Na}^{+}$and $\mathrm{K}^{+}$gradients across the plasma membrane (Figure $7 \mathrm{~b}) .{ }^{106}$ Four isoforms of the $\alpha$ subunit $(\alpha 1, \alpha 2, \alpha 3$ and $\alpha 4$ ) exhibit unique tissue distributions. The $\alpha 1$ isoform is present as the major housekeeping form in most tissues. ${ }^{106}$ In addition to the binding sites for $\mathrm{Na}^{+}, \mathrm{K}^{+}$and ATP, the $\alpha$-subunit has highly conserved binding sites for cardiac glycosides. ${ }^{106}$ All the four $\alpha$ isoforms are sensitive to ouabain in humans, whereas the $\alpha 1$ isoform is ouabainresistant in rodents. It is well established that the inhibition of $\mathrm{Na}^{+} / \mathrm{K}^{+}$-ATPase activity by cardiac glycosides leads to an increase in intracellular sodium ion levels in cardiac myocytes and subsequently an increase in calcium ion levels by $\mathrm{Ca}^{2+} / \mathrm{Na}^{+}$exchange, thereby stimulating inotropic actions. ${ }^{105}$

In addition to pumping ions, $\mathrm{Na}^{+} / \mathrm{K}^{+}$-ATPase has been shown to mediate various signal transductions in a manner independent of its function as an ion pump in response to cardiac glycosides (Figure $7 \mathrm{~b}) .{ }^{105}$ It has been shown that ouabain signals calcium oscillations through the inositol 1,4,5-triphosphate receptor that interacts with $\mathrm{Na}^{+} / \mathrm{K}^{+}$-ATPase and thereby induces NF- $\kappa \mathrm{B}$ activation at concentrations that do not inhibit $\mathrm{Na}^{+} / \mathrm{K}^{+}$-ATPase activity. ${ }^{107-109}$ In cardiac myocytes, ouabain has been reported to promote the rapid generation of reactive oxygen species, thereby inducing NF- $\kappa \mathrm{B}$ activation. ${ }^{110}$ As an early signaling pathway, $\mathrm{Na}^{+} / \mathrm{K}^{+}$-ATPase, on binding to cardiac glycosides, activates the cytoplasmic tyrosine kinase SRC, thereby activating the epidermal growth factor receptor and leading to the recruitment of adaptor proteins and the activation of the MAP kinase cascade that ultimately stimulates the mitochondrial production of reactive oxygen species. ${ }^{105,111}$

Cardenolide glycosides, such as oleandrin and digitoxin (Figure 7a), have been reported to block the NF- $\mathrm{B}$ pathway activated either constitutively or in response to stimuli. ${ }^{112-118}$ Unlike ouabain, oleandrin inhibits NF- $\kappa B$ activation upstream of $\mathrm{I} \kappa \mathrm{B}$ degradation in response to many stimuli. ${ }^{112,113}$ In macrophage, oleandrin inhibits 

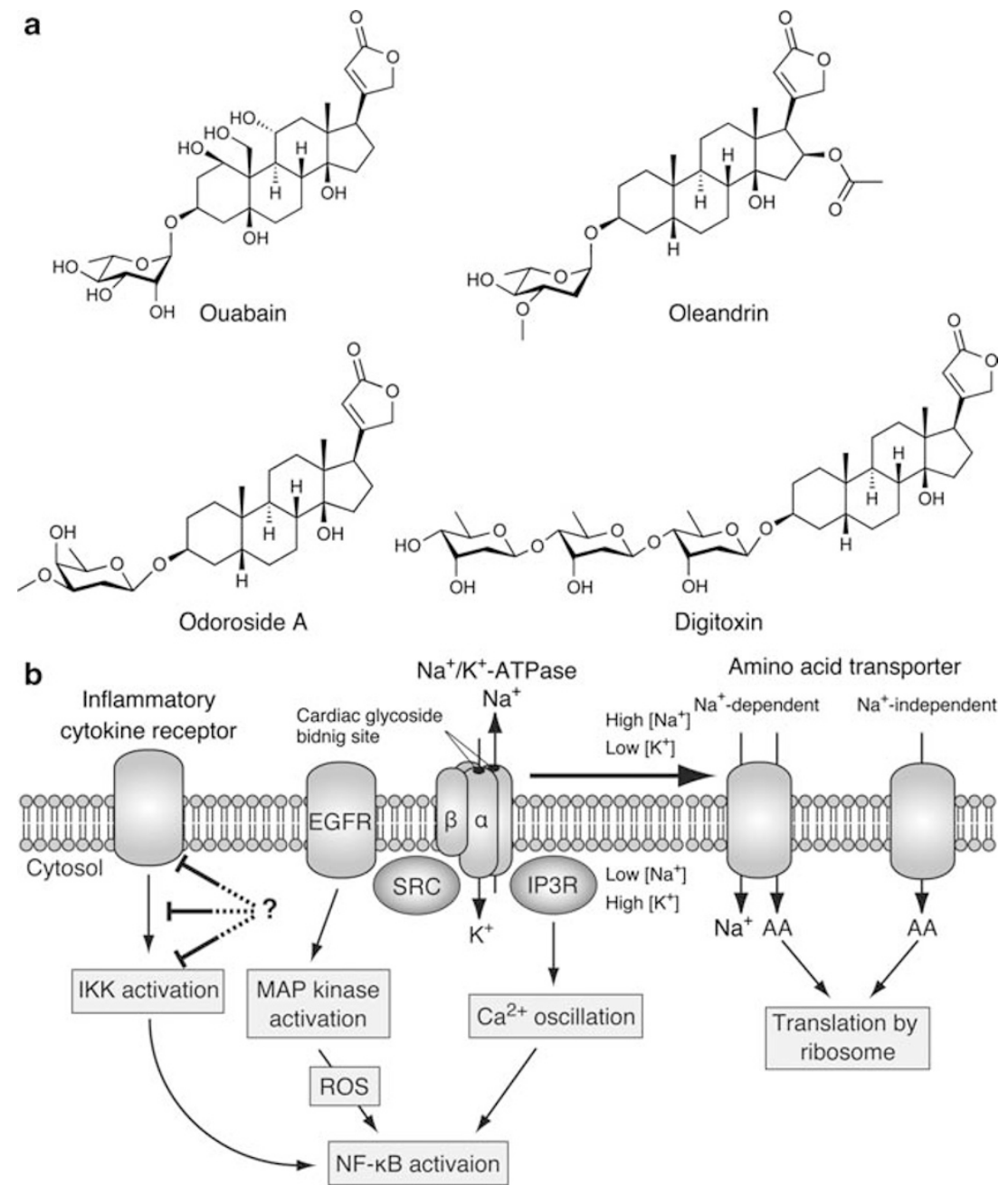

Figure 7 Structures of cardenolide glycosides and their mechanisms of actions. (a) Structures of cardenolide glycosides. (b) $\mathrm{Na}^{+} / \mathrm{K}^{+}-\mathrm{ATPase}$ is composed of $\alpha$ and $\beta$ subunits and pumps $\mathrm{Na}^{+}$out and $\mathrm{K}^{+}$in to maintain transmembrane $\mathrm{Na}^{+}$and $\mathrm{K}^{+}$gradients across the plasma membrane. Amino acid transporters couple the uptake of amino acids with the electrical and chemical gradients through $\mathrm{Na}^{+} / \mathrm{K}^{+}-$ATPase. $\mathrm{Na}^{+} / \mathrm{K}^{+}$-ATPase interacts with inositol $1,4,5-$ triphosphate (IP3R), which is responsible for $\mathrm{Ca}^{2+}$ oscillation, leading to nuclear factor- $\mathrm{KB}(\mathrm{NF}-\mathrm{KB})$ activation. $\mathrm{Na}^{+} / \mathrm{K}^{+}-\mathrm{ATPase}$ also interacts with the cytoplasmic tyrosine kinase SRC and thereby induces the activation of epidermal growth factor receptor (EGFR). EGFR recruits a set of adaptor proteins and activates the mitogen-activated protein (MAP) kinase cascade, which stimulates the mitochondrial production of reactive oxygen species (ROS), leading to $\mathrm{NF}-\kappa \mathrm{B}$ activation. Cardenolide glycosides bind to the $\alpha$-subunit of $\mathrm{Na}^{+} / \mathrm{K}^{+}-\mathrm{ATPase}$ at the extracellular region. Cardenolide glycosides exert different biological effects: the induction of NF-KB activation, the inhibition of NF-kB activation by inflammatory cytokine receptors at levels upstream of inhibitor of nuclear factor- $\mathrm{KB}$ kinase (IKK) activation and the inhibition of $\mathrm{NF}-\mathrm{\kappa B}$-inducible protein expression by blocking $\mathrm{Na}^{+}$-dependent amino acid transport.

IL-8-induced activation by downregulating IL-8 receptor expression through membrane fluidity alteration, whereas it does not affect NF$\kappa \mathrm{B}$ activation in response to many stimuli, including that of TNF- $\alpha$ and IL-1. ${ }^{115}$ It has been shown that digitoxin and oleandrin inhibit TNF- $\alpha$-induced NF- $\kappa \mathrm{B}$ activation by blocking the recruitment of TRADD to TNF-R1. ${ }^{117}$ It has also been shown that digitoxin inhibits the IL-1-induced phosphorylation of IKK, but not the IL-1-induced phosphorylation of TAK1, indicating that digitoxin inhibits IL-1induced NF- $\kappa \mathrm{B}$ activation at the IKK level. ${ }^{118}$ Therefore, cardenolide glycosides are likely to interfere with at least different steps in NF- $\mathrm{KB}$ signaling, although it remains unclear whether the inhibition of NF- $\kappa \mathrm{B}$ activation by cardenolide glycosides is related to their inhibition of $\mathrm{Na}^{+} / \mathrm{K}^{+}$-ATPase activity (Figure $7 \mathrm{~b}$ ).

We have isolated cardenolide glycosides and their related compounds from Nerium oleander and Phytolacca americana, and conducted structure-activity relationship studies of their in vitro anti-inflammatory activity. Among these compounds, odoroside A (Figure 7a) was found to inhibit ICAM-1 expression induced by TNF- $\alpha$ or IL- 1 at IC $_{50}$ values $<1 \mu$ m. ${ }^{119-123}$ Odoroside A has been shown to directly inhibit the ATP-hydrolyzing activity of $\mathrm{Na}^{+} / \mathrm{K}^{+}$ATPase as potently as ouabain. ${ }^{124}$ However, in contrast to previous studies, we have found that odoroside $A$ and ouabain affect neither TNF- $\alpha$-induced early NF- $\kappa B$ signaling pathway nor mRNA expression, but rather prevent NF- $\mathrm{BB}$-inducible protein expression by blocking $\mathrm{Na}^{+}$-dependent amino acid transport. ${ }^{124}$

Amino acid transport across the plasma membrane in mammalian cells is catalyzed by a broad range of discrete systems that consist of different gene products and distinct substrate specificities. ${ }^{125}$ Amino acid transporters are known to couple amino acid transport with the electrical and chemical gradients initiated by $\mathrm{Na}^{+} / \mathrm{K}^{+}$-ATPase (Figure 7b). ${ }^{125}$ This notion is in agreement with our finding that $\mathrm{Na}^{+}$-dependent amino acid transport is preferentially prevented by 
odoroside A and ouabain compared with $\mathrm{Na}^{+}$-independent amino acid transport. ${ }^{124}$ Inhibition of de novo protein synthesis by odoroside A has been observed at least in three cancer cell lines. ${ }^{124}$ Therefore, it seems that cardenolide glycosides generally prevent NF- $\mathrm{KB}$-inducible gene expression at the translation level. However, it is currently unclear how either the early NF- $\kappa \mathrm{B}$ signaling pathway or the late $\mathrm{NF}-\kappa \mathrm{B}-$ dependent protein expression is inhibited when cells are exposed to cardenolide glycosides. This may be influenced by the structures of cardenolide glycosides, their doses and durations, as well as cell-type specificity, including the expression levels of $\mathrm{Na}^{+} / \mathrm{K}^{+}$ATPase isoforms, amino acid transporters and signaling proteins that regulate $\mathrm{Na}^{+} / \mathrm{K}^{+}$-ATPase signal transduction.

\section{PROTEIN SYNTHESIS INHIBITORS}

Protein synthesis inhibitors, such as cycloheximide (CHX, as shown in Figure $8 \mathrm{a}$ ), are thought to block the translational stage of NF- $\mathrm{KB}-$ inducible anti-apoptotic proteins, and thus have been often used to sensitize many types of cells to TNF- $\alpha$-induced apoptosis. ${ }^{12}$ Therefore, it is believed that protein synthesis inhibitors do not affect the early NF- $\kappa \mathrm{B}$ signaling pathway on TNF- $\alpha$ stimulation. In the course of screening for microbial secondary metabolites, we have initially identified acetoxycycloheximide (Ac-CHX, as shown in Figure 8a) as an active compound that inhibits TNF- $\alpha$-induced ICAM-1 expression at 800-fold lower concentration than that used to inhibit IL-1-induced ICAM-1 expression. ${ }^{126}$ In fact, Ac-CHX shows $\sim 10$-fold stronger protein synthesis blocking activity than CHX.126,127 However, Ac-CHX has been found to block TNF- $\alpha$-induced I $\kappa \mathrm{B} \alpha$ degradation, but not IL-1-induced I $\mathrm{I} \mathrm{B} \alpha$ degradation, indicating that Ac-CHX specifically inhibits the TNF- $\alpha$-induced early NF- $\kappa \mathrm{B}$ signaling pathway. ${ }^{126}$ As a novel molecular mechanism, we have recently shown that Ac-CHX inhibits TNF- $\alpha$-induced NF- $\kappa \mathrm{B}$ activation by inducing the ectodomain shedding of cell-surface TNF-R1 (Figure $8 \mathrm{~b}$ ). ${ }^{128} \mathrm{CHX}$ is also capable of inducing the ectodomain shedding of TNF-R1, although $\sim 100$-fold higher concentrations are required compared with Ac-CHX. ${ }^{128}$

Tumor necrosis factor- $\alpha$-converting enzyme (TACE), also referred to as a disintegrin and metalloprotease 17 (ADAM17), is a cell-surface type I transmembrane protein that was initially identified to process membrane-bound precursor TNF- $\alpha$ to its mature soluble form. ${ }^{129,130}$ Ectodomain shedding is a critical posttranslational mechanism for the regulation of the function of membrane-anchored ligands and receptors. In addition to TNF- $\alpha$, TACE is able to process other ligands and receptors, such as TNF-R1 and TNF-R2. ${ }^{129,130}$ It has been shown that Ac-CHX induces the cleavage of cell-surface TNF-R1 into smaller soluble forms in a TACE-dependent manner and that the inhibition of TACE activity reverses TNF- $\alpha$-induced NF- $\kappa B$ activation in Ac-CHXtreated cells. $^{128}$

Ribotoxic stress response caused by some protein synthesis inhibitors triggers the activation of the MAP kinase superfamily, thereby eliciting cellular responses such as gene expression and apoptosis. ${ }^{126-128,131-135}$ Protein synthesis inhibitors that share the property of inducing alterations in the $28 \mathrm{~S}$ rRNA, such as anisomycin (Figure 8a), are known to induce ribotoxic stress response. ${ }^{131-133}$ With regard to the structure-activity relationship, it seems that the acetoxyl groups of Ac-CHX and anisomycin are crucial to induce ribotoxic stress response, as their deacetoxyl and deacetyl analogs, respectively, are much less active to elicit ribotoxic stress response. ${ }^{126-128,133}$

Extracellular signal-regulated kinase (ERK) and p38 MAP kinase have been reported to regulate ectodomain shedding mediated by TACE. ${ }^{136-140}$ In fact, Ac-CHX, and to a much lesser extent CHX, are able to promote the sustained activation of ERK and p38 MAP a

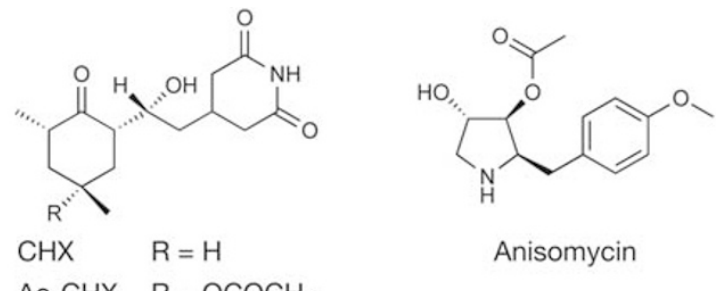

b

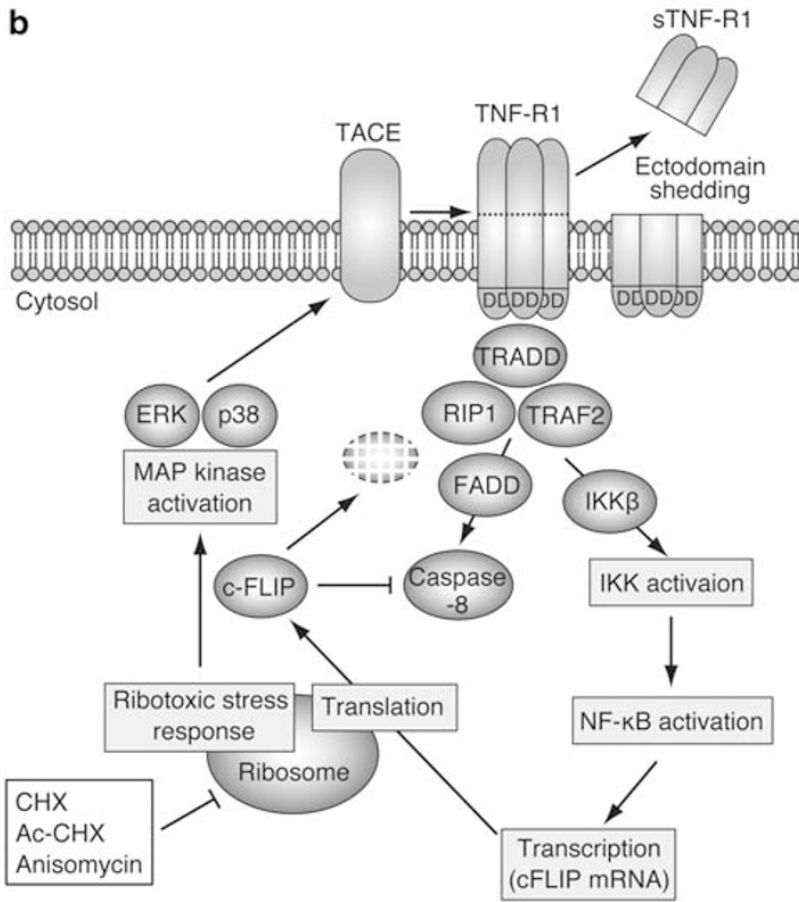

Figure 8 Structures of protein synthesis inhibitors and their mechanisms of actions on nuclear factor- $\mathrm{\kappa B}(\mathrm{NF}-\mathrm{\kappa B})$ and apoptosis signaling pathways. (a) Structures of protein synthesis inhibitors. (b) Protein synthesis inhibitors such as acetoxycycloheximide (Ac-CHX) and anisomycin induce ribotoxic stress response, which triggers the activation of the mitogen-activated protein (MAP) kinase superfamily. Extracellular signal-regulated kinase (ERK) and p38 MAP kinase are responsible for the induction of the ectodomain shedding of TNF receptor 1 (TNF-R1) by TNF- $\alpha$-converting enzyme (TACE), thereby preventing the TNF-R1-dependent NF-KB signaling pathway. C-FLIP (cellular FADD-like IL-1 $\beta$-converting enzyme-inhibitory protein) is a short-lived protein regulated by the ubiquitin-proteasome pathway, but upregulated in an NF-кB-dependent manner. Protein synthesis inhibitors such as cycloheximide ( $\mathrm{CHX}$ ) prevent the de novo synthesis of c-FLIP at the level of translation, thereby allowing the activation of caspase-8.

kinase. ${ }^{127,131,132,134}$ The MEK (MAP/ERK kinase) inhibitor, U0126, and the p38 MAP kinase inhibitor, SB203580, prevent ectodomain shedding of TNF-R1 induced by Ac-CHX.134 The nonsteroidal anti-inflammatory drug, sodium salicylate, is known to block IKB degradation in response to stimuli. ${ }^{141}$ In addition to the direct inhibition of IKK $\beta$ activity by sodium salicylate, ${ }^{142}$ it has been shown that sodium salicylate blocks TNF- $\alpha$-mediated I $\mathrm{B} \alpha$ phosphorylation through p38 MAP kinase activation and that it causes rapid shedding of TNF-R1 in a p38 MAP kinase-dependent manner. ${ }^{143-145}$ Therefore, these findings are in line with our findings that ERK and p38 MAP kinase induce the downregulation of TNF-R1 by ribotoxic stress response. ${ }^{128,134}$ 
Table 2 Profiles of natural and synthetic compounds that inhibit NF-кB signaling pathway

\begin{tabular}{|c|c|c|c|c|}
\hline Compound & Origin & Molecular target ${ }^{\mathrm{a}}$ & Concentration $(\mu M)^{\mathrm{b}}$ & Reference \\
\hline Arsenite & Environmental toxin & $\mathrm{IKK} \beta$ & $12.5-100$ & Kapahi et al..$^{53}$ \\
\hline Auranofin & Gold compound & IKK $\beta$ & $10-30$ & Jeon et al. 59 \\
\hline Berberine & Plant & IKK $\beta$ & $10-50$ & Pandey et al. ${ }^{63}$ \\
\hline Butein & Plant & IKK $\beta$ & $10-50$ & Pandey et al. ${ }^{62}$ \\
\hline Celastrol & Plant (Celastrus orbiculatus) & IKK $\beta$ & $0.22-2.2$ & Lee et $a l .61$ \\
\hline Cycloepoxydon & Deuteromycete & ND & $4.2-8.4^{\mathrm{c}}$ & Gehrt et al. ${ }^{84}$ \\
\hline $15-$ Deoxy- $\Delta^{12,14}-$ PGJ $_{2}$ & Natural prostaglandin derivative & IKK $\beta / p 65$ & $1-6$ & Rossi et al. ${ }^{54}$; Straus et al. ${ }^{56}$ \\
\hline$(-)-D H M E Q$ & Synthetic derivative of epoxyquinomycin $\mathrm{C}^{\mathrm{d}}$ & Rel family proteins & $2.7-27$ & Matsumoto et al. ${ }^{86}$; Ariga et al. ${ }^{97}$ \\
\hline Digitoxin & Plant & $\mathrm{Na}^{+} / \mathrm{K}^{+}-$ATPase & $0.003-0.1$ & $\begin{array}{l}\text { Tabary et al. }{ }^{116} \text {; Yang et al. }{ }^{117} \text {; } \\
\text { Jagielska et al. }{ }^{118}\end{array}$ \\
\hline Helenalin & Plant & p65 & $10-40$ & Lyss et al. ${ }^{68}$; García-Piñeres et al. ${ }^{69}$ \\
\hline Jesterone dimer & Synthetic derivative of jesterone $e^{e}$ & IKK $\beta$ & $2.5-20$ & Liang et al. ${ }^{90}$ \\
\hline Manumycin A & Streptomyces parvulus & IKK $\beta$ & $2-20$ & Bernier et al. 60 \\
\hline Oleandrin & Plant & $\mathrm{Na}^{+} / \mathrm{K}^{+}-$ATPase & $0.017-17$ & $\begin{array}{l}\text { Manna et al. }{ }^{112} ; \text { Sreenivasan et al. }{ }^{113} ; \\
\text { Srivastava et al. }{ }^{114} ; \text { Manna et al. }{ }^{115}\end{array}$ \\
\hline 5Z-7-oxozeaenol & Fungus & TAK1 & $0.083^{c}$ & Ninomiya-Tsuji et al. ${ }^{96}$ \\
\hline Panepoxydone & Lentinus crinitus & ND & $7.15-9.52^{c}$ & Erkel et al. ${ }^{91}$ \\
\hline Parthenolide & Plant & IKK $\beta / p 65$ & $5-40$ & $\begin{array}{l}\text { García-Piñeres et al. }{ }^{69} \text {; Hehner et al. }{ }^{71} \text {; } \\
\text { Hehner et al. }{ }^{72}\end{array}$ \\
\hline Peperomin E & Plant (Peperomia dindygulensis) & ND & $10.5^{c}$ & Wu et al. ${ }^{81}$ \\
\hline SRC2 & Synthetic derivative of $L-\alpha$-santonin & ND & $5.9^{c}$ & Kawai et al. ${ }^{80}$ \\
\hline Xanthohumol & Plant & IKK $\beta / p 65$ & $10-50$ & Harikumar et al. ${ }^{64}$ \\
\hline
\end{tabular}

Abbreviations: CDDO-Im, 1-(2-cyano-3,12-dioxooleana-1,9-dien-28-oyl)imidazole; CDDO-Me, 2-cyano-3,12-dioxooleana-1,9-dien-28-oic acid methyl ester; DHMEQ, dehydroxymethylepoxyquinomicin; IKK $\beta$, inhibitor of nuclear factor-kB kinase- $\beta$; ND, not determined; NF-KB, nuclear factor-kB; SRC2, (11S)-2 $\alpha$-bromo-3-oxoeudesmano-13,6 $\alpha$-lactone; TAK1, tumor growth factor- $\beta$-activated kinase. ${ }^{a}$ Molecular targets in the NF-KB signaling pathways or specific intracellular targets are shown.

${ }^{\mathrm{b}}$ The concentration range used to inhibit NF-kB activation in the cell-based assay is shown.

${ }^{\mathrm{T}} \mathrm{The} \mathrm{IC}_{50}$ values are shown

dProduced by Amycolatopsis sp.

eproduced by Pestalotiopsis jesteri.

In the presence of TACE inhibitors, TNF- $\alpha$-induced caspase- 8 activation is greatly increased when A549 cells are treated with $\mathrm{CHX}$ or Ac-CHX.128 As TACE is widely expressed in adult and fetal tissues, TNF- $\alpha / \mathrm{CHX}$-induced apoptosis may be more pronounced in various types of cells in the presence of TACE inhibitors. Given that TNF- $\alpha$-induced NF- $\kappa B$ activation induces the upregulation of $c$-FLIP, TACE-dependent ectodomain shedding induced by ERK and p38 MAP kinase is regarded as a posttranslational mechanism that immediately controls long-lived TNF-R1 on the cell surface (Figure 8b). Therefore, the ectodomain shedding of cell-surface TNF-R1 is likely to have a role in conferring resistance to TNF- $\alpha$ induced apoptosis and in delaying the onset of TNF- $\alpha$-induced apoptosis for a certain period.

\section{CONCLUSION}

In this review, the identification and biological properties of NF- $\kappa B$ inhibitors (summarized in Table 2), which are classified into natural and synthetic IKK inhibitors, sesquiterpene lactones, epoxyquinoids, cardenolide glycosides and protein synthesis inhibitors have been described. Some of them are often used as specific NF- $\kappa B$ inhibitors and as bioprobes to characterize intracellular biological responses and cell functions in various experimental models. Although not described in this review, there are still many other interesting small molecules with unique structures and inhibitory profiles. Therefore, the elucidation of their molecular mechanisms would contribute to characterizing the NF- $\kappa \mathrm{B}$ signaling pathway at the molecular level as well as to developing novel lead compounds that target the NF- $\mathrm{BB}$ signaling pathway in response to pro-inflammatory cytokines.

\section{ACKNOWLEDGEMENTS}

I thank Professor Masaya Imoto for giving me an opportunity to prepare this review.

1 Karin, M. \& Greten, F. R. NF-KB: linking inflammation and immunity to cancer development and progression. Nat. Rev. Immunol. 5, 749-759 (2005).

2 Baud, V. \& Karin, M. Is NF-KB a good target for cancer therapy? Hopes and pitfalls. Nat. Rev. Drug Discov. 8, 33-40 (2009).

3 Ghosh, S. \& Hayden, M. S. New regulators of NF-kB in inflammation. Nat. Rev. Immunol. 8, 837-848 (2008).

4 Hayden, M. S. \& Ghosh, S. Shared principles in NF-KB signaling. Cel/ 132, 344-362 (2008).

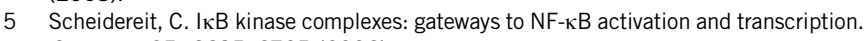
Oncogene 25, 6685-6705 (2006).

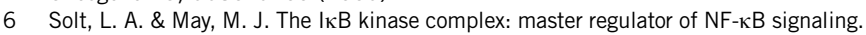
Immunol. Res. 42, 3-18 (2008). 
7 Lee, F. S., Peters, R. T., Dang, L. C. \& Maniatis, T. MEKK1 activates both IкB kinase $\alpha$ and IкB kinase $\beta$. Proc. Natl Acad. Sci. USA 95, 9319-9324 (1998).

8 Zandi, E., Chen, Y. \& Karin, M. Direct phosphorylation of IKB by IKK $\alpha$ and IKK $\beta$. discrimination between free and NF-kB-bound substrate. Science 281, 1360-1363 (1998).

9 Chen, Z. J. Ubiquitin signalling in the NF-кB pathway. Nat. Cell Biol. 7, 758-765 (2005)

10 Bhoj, V. G. \& Chen, Z. J. Ubiquitylation in innate and adaptive immunity. Nature 458, 430-437 (2009)

11 Locksley, R. M., Killeen, N. \& Lenardo, M. J. The TNF and TNF receptor superfamilies: integrating mammalian biology. Cell 104, 487-501 (2001).

12 Aggarwal, B. B. Signalling pathways of the TNF superfamily: a double-edged sword. Nat. Rev. Immunol. 3, 745-756 (2003).

13 Micheau, O. \& Tschopp, J. Induction of TNF receptor I-mediated apoptosis via two sequential signaling complexes. Cell 114, 181-190 (2003).

14 Ea, C. K., Deng, L., Xia, Z. P., Pineda, G. \& Chen, Z. J. Activation of IKK by TNF $\alpha$ requires site-specific ubiquitination of RIP1 and polyubiquitin binding by NEMO. Mol. Cell 22, 245-257 (2006)

15 Li, H., Kobayashi, M., Blonska, M., You, Y. \& Lin, X. Ubiquitination of RIP is required for tumor necrosis factor $\alpha$-induced NF-kB activation. J. Biol. Chem. 281, 13636-13643 (2006).

16 Wu, C. J., Conze, D. B., Li, T., Srinivasula, S. M. \& Ashwell, J. D. Sensing of Lys 63linked polyubiquitination by NEMO is a key event in NF- $\mathrm{\kappa B}$ activation. Nat. Cell Biol. 8, 398-406 (2006).

17 Kataoka, T. The caspase-8 modulator c-FLIP. Crit. Rev. Immunol. 25, 31-58 (2005)

18 Budd, R. C., Yeh, W. C. \& Tschopp, J. cFLIP regulation of lymphocyte activation and development. Nat. Rev. Immunol. 6, 196-204 (2006).

19 Chang, L. et al. The E3 ubiquitin ligase Itch couples JNK activation to TNF $\alpha$-induced cell death by inducing c-FLIPL turnover. Cell 124, 601-613 (2006).

20 Janssens, S. \& Beyaert, R. Functional diversity and regulation of different interleukin1 receptor associated kinase (IRAK) family members. Mol. Cell 11, 293-302 (2003).

21 Shimada, T. et al. IKK-i, a novel lipopolysaccharide-inducible kinase that is related to IкB kinase. Int. Immunol. 11, 1357-1362 (1999).

22 Peters, R. T., Liao, S. M. \& Maniatis, T. IKK is part of a novel PMA-inducible I $\kappa B$ kinase complex. Mol. Cell 5, 513-522 (2000).

23 Kishore, N. et al. IKK-i and TBK-1 are enzymatically distinct from the homologous enzyme IKK-2: comparative analysis of recombinant human IKK-i, TBK-1, and IKK-2. J. Biol. Chem. 277, 13840-13847 (2002).

24 Hideshima, T. et al. NF-kB as a therapeutic target in multiple myeloma. J. Biol. Chem. 277, 16639-16647 (2002).

25 Castro, A. C. et al. Novel IKK inhibitors: $\beta$-carbolines. Bioorg. Med. Chem. Lett. 13, 2419-2422 (2003).

26 Nagashima, K. et al. Rapid TNFR1-dependent lymphocyte depletion in vivo with a selective chemical inhibitor of IKK $\beta$. Blood 107, 4266-4273 (2006).

27 Wen, D. et al. A selective small molecule $1 \kappa B$ kinase $\beta$ inhibitor blocks nuclear factor $\kappa \mathrm{B}$-mediated inflammatory responses in human fibroblast-like synoviocytes, chondrocytes, and mast cells. J. Pharmacol. Exp. Ther. 317, 989-1001 (2006).

28 Kishore, N. et al. A selective IKK-2 inhibitor blocks NF-KB-dependent gene expression in interleukin-1 $\beta$-stimulated synovial fibroblasts. J. Biol. Chem. 278, 32861-32871 (2003)

29 Baxter, A. et al. Hit-to-lead studies: the discovery of potent, orally active, thiophenecarboxamide IKK-2 inhibitors. Bioorg. Med. Chem. Lett. 14, 2817-2822 (2004).

30 Bonafoux, D. et al. Inhibition of IKK-2 by 2-[(aminocarbonyl)amino]-5-acetylenyl-3thiophenecarboxamides. Bioorg. Med. Chem. Lett. 15, 2870-2875 (2005).

31 Podolin, P. L et al. Attenuation of murine collagen-induced arthritis by a novel, potent, selective small molecule inhibitor of $\mathrm{I} \mathrm{KB}$ kinase 2, TPCA-1 (2-[(aminocarbonyl)amino]-5-(4-fluorophenyl)-3-thiophenecarboxamide), occurs via reduction of proinflammatory cytokines and antigen-induced T cell proliferation. J. Pharmacol. Exp. Ther. 312, 373-381 (2005).

32 Sugiyama, H. et al. Synthesis and structure activity relationship studies of benzothieno[3,2-b]furan derivatives as a novel class of IKK $\beta$ inhibitors. Chem. Pharm. Bull. 55, 613-624 (2007).

33 Murata, T. et al. Discovery of novel and selective IKK- $\beta$ serine-threonine protein kinase inhibitors. Part 1. Bioorg. Med. Chem. Lett. 13, 913-918 (2003)

34 Murata, T. et al. Synthesis and structure-activity relationships of novel IKK- $\beta$ inhibitors. Part 3: orally active anti-inflammatory agents. Bioorg. Med. Chem. Lett. 14, 4019-4022 (2004)

35 Sanda, T. et al. Growth inhibition of multiple myeloma cells by a novel IкB kinase inhibitor. Clin. Cancer Res. 11, 1974-1982 (2005).

36 Frelin, C. et al. AS602868, a pharmacological inhibitor of IKK2, reveals the apoptotic potential of TNF- $\alpha$ in Jurkat leukemic cells. Oncogene 22, 8187-8194 (2003).

37 Heckmann, A. et al. IKK2 inhibitor alleviates kidney and wasting diseases in a murine model of human AIDS. Am. J. Pathol. 164, 1253-1262 (2004).

38 Burke, J. R. et al. BMS-345541 is a highly selective inhibitor of I $\mathrm{KB}$ kinase that binds at an allosteric site of the enzyme and blocks NF-kB-dependent transcription in mice. J. Biol. Chem. 278, 1450-1456 (2003).

39 Beaulieu, F. et al. Synthesis and biological evaluation of 4-amino derivatives of benzimidazoquinoxaline, benzimidazoquinoline, and benzopyrazoloquinazoline as potent IKK inhibitors. Bioorg. Med. Chem. Lett. 17, 1233-1237 (2007).

40 Belema, M. et al. Synthesis and structure-activity relationship of imidazo(1,2a)thieno(3,2-e)pyrazines as IKK- $\beta$ inhibitors. Bioorg. Med. Chem. Lett. 17, 4284-4289 (2007).

41 Onai, Y. et al. Inhibition of $\mid \kappa B$ phosphorylation in cardiomyocytes attenuates myocardial ischemia/reperfusion injury. Cardiovasc. Res. 63, 51-59 (2004).
42 Tanaka, A. et al. A novel NF-kB inhibitor, IMD-0354, suppresses neoplastic proliferation of human mast cells with constitutively activated c-kit receptors. Blood $\mathbf{1 0 5}$, 2324-2331 (2005)

43 Tegeder, I. et al. Specific inhibition of IאB kinase reduces hyperalgesia in inflammatory and neuropathic pain models in rats. J. Neurosci. 24, 1637-1645 (2004).

44 Waelchli, R. et al. Design and preparation of 2-benzamido-pyrimidines as inhibitors of IKK. Bioorg. Med. Chem. Lett. 16, 108-112 (2006).

45 Bamborough, P. et al. 5-(1 H-Benzimidazol-1-yl)-3-alkoxy-2-thiophenecarbonitriles as potent, selective, inhibitors of IKK- $\varepsilon$ kinase. Bioorg. Med. Chem. Lett. 16, 6236-6240 (2006).

46 Christopher, J. A. et al. The discovery of 2-amino-3,5-diarylbenzamide inhibitors of IKK- $\alpha$ and IKK- $\beta$ kinases. Bioorg. Med. Chem. Lett. 17, 3972-3977 (2007).

47 Christopher, J. A. et al. Discovery of 6 -aryl-7-alkoxyisoquinoline inhibitors of $1 \kappa B$ kinase- $\beta$ (IKK- $\beta$ ). J. Med. Chem. 52, 3098-3102 (2009).

48 Liddle, J. et al. 4-Phenyl-7-azaindoles as potent and selective IKK2 inhibitors. Bioorg. Med. Chem. Lett. 19, 2504-2508 (2009).

49 Mbalaviele, G. et al. A novel, highly selective, tight binding I KB kinase-2 (IKK-2) inhibitor: a tool to correlate IKK-2 activity to the fate and functions of the components of the nuclear factor- $\mathrm{\kappa B}$ pathway in arthritis-relevant cells and animal models. J. Pharmacol. Exp. Ther. 329, 14-25 (2009).

50 Sommers, C. D. et al. Novel tight-binding inhibitory factor- $\kappa B$ kinase (IKK-2) inhibitors demonstrate target-specific anti-inflammatory activities in cellular assays and following oral and local delivery in an in vivo model of airway inflammation. J. Pharmacol. Exp. Ther. 330, 377-388 (2009).

51 Ling, L., Cao, Z. \& Goeddel, D. V. NF-KB-inducing kinase activates IKK- $\alpha$ by phosphorylation of Ser-176. Proc. Natl Acad. Sci. USA 95, 3792-3797 (1998).

52 Delhase, M., Hayakawa, M., Chen, Y. \& Karin, M. Positive and negative regulation of IKB kinase activity through IKK $\beta$ subunit phosphorylation. Science 284, 309-313 (1999).

53 Kapahi, P. et al. Induction of NF-kB activation by arsenite through reaction with a critical cysteine in the activation loop of IKB kinase. J. Biol. Chem. 275, 3606236066 (2000)

54 Rossi, A. et al. Anti-inflammatory cyclopentenone prostaglandins are direct inhibitors of I $\mathrm{B}$ kinase. Nature 403, 103-108 (2000).

55 Byun, M. S., Choi, J. \& Jue, D. M. Cysteine- 179 of IкB kinase $\beta$ plays a critical role in enzyme activation by promoting phosphorylation of activation loop serines. Exp. Mol. Med. 38, 546-552 (2006).

56 Straus, D. S. et al. 15-Deoxy- $\Delta^{12,14}$-prostaglandin $\mathrm{J}_{2}$ inhibits multiple steps in the NF-kB signaling pathway. Proc. Natl Acad. Sci. USA 97, 4844-4849 (2000)

57 Ahmad, R., Raina, D., Meyer, C., Kharbanda, S. \& Kufe, D. Triterpenoid CDDO-Me blocks the NF-KB pathway by direct inhibition of IKK $\beta$ on Cys-179. J. Biol. Chem. 281, 35764-35769 (2006).

58 Yore, M. M., Liby, K. T., Honda, T., Gribble, G. W. \& Sporn, M. B. The synthetic triterpenoid 1-[2-cyano-3,12-dioxooleana-1,9(11)-dien-28-oyl]imidazole blocks nuclear factor- $\mathrm{\kappa B}$ activation through direct inhibition of $\mathrm{I} \mathrm{\kappa B}$ kinase $\beta$. Mol. Cancer Ther. 5, 3232-3239 (2006)

59 Jeon, K. I., Byun, M. S. \& Jue, D. M. Gold compound auranofin inhibits $1 \kappa B$ kinase (IKK) by modifying Cys-179 of IKK $\beta$ subunit. Exp. Mol. Med. 35, 61-66 (2003).

60 Bernier, M. et al. Binding of manumycin A inhibits I $\mathrm{kB}$ kinase $\beta$ activity. J. Biol. Chem. 281, 2551-2561 (2006)

61 Lee, J. $\mathrm{H}$. et al. Inhibition of NF- $\mathrm{KB}$ activation through targeting $\mathrm{I} \kappa \mathrm{B}$ kinase by celastrol, a quinone methide triterpenoid. Biochem. Pharmacol. 72, 1311-1321 (2006).

62 Pandey, M. K et al. Butein, a tetrahydroxychalcone, inhibits nuclear factor (NF)- $\mathrm{KB}$ and NF-kB-regulated gene expression through direct inhibition of $\mathrm{I} \kappa \mathrm{B} \alpha$ kinase $\beta$ on cysteine 179 residue. J. Biol. Chem. 282, 17340-17350 (2007)

63 Pandey, M. K. et al. Berberine modifies cysteine 179 of $\mathrm{I} \kappa \mathrm{B} \alpha$ kinase, suppresses nuclear factor- $\mathrm{KB}$-regulated antiapoptotic gene products, and potentiates apoptosis. Cancer Res. 68, 5370-5379 (2008)

64 Harikumar, K. B. et al. Modification of the cysteine residues in $1 \kappa B \alpha$ kinase and NF- $\kappa B$ (p65) by xanthohumol leads to suppression of NF-kB-regulated gene products and potentiation of apoptosis in leukemia cells. Blood 113, 2003-2013 (2009).

65 Palempalli, U. D. et al. Gambogic acid covalently modifies $1 \kappa B$ kinase- $\beta$ subunit to mediate suppression of lipopolysaccharide-induced activation of NF- $\mathrm{KB}$ in macrophage. Biochem. J. 419, 401-409 (2009).

66 Schmidt, T. J. Helenanolide-type sesquiterpene lactones-III. Rates and stereochemistry in the reaction of helenalin and related helenanolides with sulfhydryl containing biomolecules. Bioorg. Med. Chem. 5, 645-653 (1997).

67 Lyss, G., Schmidt, T. J., Merfort, I. \& Pahl, H. L. Helenalin, an anti-inflammatory sesquiterpene lactone from Arnica, selectively inhibits transcription factor NF- $\mathrm{kB}$. Biol. Chem. 378, 951-961 (1997).

68 Lyss, G., Knorre, A., Schmidt, T. J., Pahl, H. L. \& Mefort, I. The anti-inflammatory sesquiterpene lactone helenalin inhibits the transcription factor NF- $\mathrm{KB}$ by directly targeting p65. J. Biol. Chem. 273, 33508-35516 (1998).

69 García-Piñeres, A. J. et al. Cysteine 38 in p65/NF-kB plays a crucial role in DNA binding inhibition by sesquiterpene lactones. J. Biol. Chem. 276, 39713-39720 (2001).

70 Bork, P. M. Schmitz, M. L., Kuhnt, M., Escher, C. \& Heinrich, M. Sesquiterpene lactone containing Mexican Indian medicinal plants and pure sesquiterpene lactones as potent inhibitors of transcription factor NF-кB. FEBS Lett. 402, 85-90 (1997).

71 Hehner, S. P. et al. Sesquiterpene lactones specifically inhibit activation of NF- $\kappa$ B by preventing the degradation of $\mid \kappa \mathrm{K}-\alpha$ and IKB- $\beta$. J. Biol. Chem. 273, 1288-1297 (1998) 
72 Hehner, S. P., Hofmann, T. G., Dröge, W. \& Schmitz, M. L. The antiinflammatory sesquiterpene lactone parthenolide inhibits $\mathrm{NF}-\kappa \mathrm{B}$ by targeting the $1 \kappa \mathrm{B}$ kinase complex. J. Immunol. 163, 5617-5623 (1999).

73 Kwok, B. H. B., Koh, B., Ndubuisi, M. I., Elofsson, M. \& Crews, C. M. The antiinflammatory natural product parthenolide from the medicinal herb Feverfew directly binds to and inhibits IкB kinase. Chem. Biol. 8, 759-766 (2001).

74 García-Piñeres, A. J., Lindenmeyer, M. T. \& Mefort, I. Role of cysteine residues of p65/ $\mathrm{NF}-\kappa \mathrm{B}$ on the inhibition by the sesquiterpene lactone parthenolide and $\mathrm{N}$-ethyl maleimide, and on its transactivating potential. Life Sci. 75, 841-856 (2004).

$75 \mathrm{Kim}, \mathrm{B}$. H. et al. Artemisolide is a typical inhibitor of $\mathrm{I}_{\kappa} \mathrm{B}$ kinase $\beta$ targeting cysteine179 residue and down-regulates NF-kB-dependent TNF- $\alpha$ expression in LPS-activated macrophages. Biochem. Biophys. Res. Commun. 361, 593-598 (2007).

76 Yuuya, S. et al. Guaianolides as immunomodulators. Synthesis and biological activities of dehydrocostus lactone, mokko lactone, eremanthin, and their derivatives. J. Nat. Prod. 62, 22-30 (1999).

77 Higuchi, Y. et al. Synthetic approach to exo-endo cross-conjugated cyclohexadienones and its application to the syntheses of dehydrobrachylaenolide, isodehydrochamaecynone, and trans-isodehydrochamaecynone. J. Nat. Prod. 66, 588-594 (2003).

78 Zhang, S. et al. Bioactive guaianolides from Siyekucai (Ixeris chinensis). J. Nat. Prod. 69, 1425-1428 (2006).

79 Siedle, B. et al. Quantitative structure-activity relationship of sesquiterpene lactones as inhibitors of the transcription factor NF-кB. J. Med. Chem. 47, 6042-6054 (2004).

80 Kawai, S. et al. Santonin-related compound 2 inhibits the expression of ICAM-1 in response to IL-1 stimulation by blocking the signaling pathway upstream of $1 \kappa \mathrm{B}$ degradation. Immunopharmacology 48, 129-135 (2000).

81 Wu, J. et al. Bioactive secolignans from Peperomia dindygulensis. J. Nat. Prod. 69, 790-794 (2006)

$82 \mathrm{Xu}, \mathrm{S}$. et al. Bioactive compounds from Peperomia pellucida. J. Nat. Prod. 69, 247250 (2006).

83 Tsutsui, C. et al. Peperomins as anti-inflammatory agents that inhibit the NF-kB signaling pathway. Bioorg. Med. Chem. Lett. 19, 4084-4087 (2009).

84 Gehrt, A., Erkel, G., Anke, T. \& Sterner, 0. Cycloepoxydon, 1-hydroxy-2-hydroxymethyl-3-pent-1-enylbenzene and 1-hydroxy-2-hydroxymethyl-3-pent-1,3-dienylbenzene, new inhibitors of eukaryotic signal transduction. J. Antibiot. 51, 455-463 (1998).

$85 \mathrm{Li}, \mathrm{C}$. et al. Total synthesis of the NF- $\mathrm{KB}$ inhibitor (-)-cycloepoxydon: utilization of tartrate-mediated nucleophilic epoxydation. J. Am. Chem. Soc. 123, 11308-11309 (2001)

86 Matsumoto, N. et al. Synthesis of NF-kB activation inhibitors derived from epoxyquinomycin C. Bioorg. Med. Chem. Lett. 10, 865-869 (2000)

$87 \mathrm{Li}, \mathrm{C}$. et al. Angiogenesis inhibitor epoxyquinol A: total synthesis and inhibition of transcription factor NF-кB. Org. Lett. 4, 3267-3270 (2002).

88 Kamiyama, H. et al. Epoxyquinol $\mathrm{B}$, a naturally occurring pentaketide dimer, inhibits NF-KB signaling by crosslinking TAK1. Biosci. Biotechnol. Biochem. 72, 1894-1900 (2008).

$89 \mathrm{Hu}, \mathrm{Y}$. et al. Exploring chemical diversity of epoxyquinoid natural products: synthesis and biological activity of (-)-jesterone and related molecules. Org. Lett. 3, 1649-1652 (2001).

90 Liang, M. C. et al. Jesterone dimer, a synthetic derivative of the fungal metabolite jestrone, blocks activation of transcription factor nuclear factor $\kappa B$ by inhibiting the inhibitor of $\kappa B$ kinase. Mol. Pharmacol. 64, 123-131 (2003).

91 Erkel, G., Anke, T. \& Sterner, O. Inhibition of NF-kB activation by panepoxydone. Biochem. Biophys. Res. Commun. 226, 214-221 (1996).

92 Kakeya, $\mathrm{H}$. et al. Epoxyquinol $\mathrm{A}$, a highly functionalized pentaketide dimer with antiangiogenic activity isolated from fungal metabolites. J. Am. Chem. Soc. 124, 3496-3497 (2002)

93 Kakeya, $\mathrm{H}$. et al. Epoxyquinol B, a fungal metabolite with a potent antiangiogenic activity. J. Antibiot. 55, 829-831 (2002).

94 Liang, M. C. et al. Inhibition of transcription factor NF-KB signaling proteins IKK $\beta$ and p65 through specific cysteine residues by epoxyquinone $A$ monomer: correlation with its anti-cancer cell growth activity. Biochem. Pharmacol. 71, 634-645 (2006).

95 Kamiyama, H. et al. Fungal metabolite, epoxyquinol B, crosslinks proteins by epoxythiol conjugation. J. Antibiot. 61, 94-97 (2008).

96 Ninomiya-Tsuji, J. et al. A resorcylic acid lactone, 5Z-7-oxozeaenol, prevents inflammation by inhibiting the catalytic activity of TAK1 MAPK kinase kinase. J. Biol. Chem. 278, 18485-18490 (2003).

97 Ariga, A., Namekawa, J., Matsumoto, N., Inoue, J. \& Umezawa, K. Inhibition of tumor necrosis factor- $\alpha$-induced nuclear translocation and activation of NF- $\kappa B$ by dehydroxymethylepoxyquinomycin. J. Biol. Chem. 277, 24625-24630 (2002).

98 Yamamoto, M., Horie, R., Takeiri, M., Kozawa, I. \& Umezawa, K. Inactivation of NF-кB components by covalent binding of (-)-dehydroxymethylepoxyquinomycin to specific cysteine residues. J. Med. Chem. 51, 5780-5788 (2008).

99 Miyake, Y., Kakeya, H., Kataoka, T. \& Osada, H. Epoxycyclohexenone inhibits Fasmediated apoptosis by blocking activation of pro-caspase- 8 in the death-inducing signaling complex. J. Biol. Chem. 278, 11213-11220 (2003).

100 Kakeya, H. et al. Novel non-peptide inhibitors targeting death receptor-mediated apoptosis. Bioorg. Med. Chem. Lett. 13, 3743-3746 (2003).

101 Bando, M. et al. The mycotoxin penicillic acid inhibits Fas ligand-induced apoptosis by blocking self-processing of caspase- 8 in death-inducing signaling complex. J. Biol. Chem. 278, 5786-5793 (2003).
102 Mitsui, T., Miyake, Y., Kakeya, H., Osada, H. \& Kataoka, T. ECH, an epoxycyclohexenone derivative that specifically inhibits Fas ligand-dependent apoptosis in CTLmediated cytotoxicity. J. Immunol. 172, 3428-3436 (2004).

103 Mitsui, T. et al. RKTS-33, an epoxycyclohexenone derivative that specifically inhibits Fas ligand-dependent apoptosis in CTL-mediated cytotoxicity. Biosci. Biotechnol. Biochem. 69, 1923-1928 (2005).

104 Kataoka, T. et al. Concanamycin A, a powerful tool for characterization and estimation of contribution of perforin- and Fas-based lytic pathways in cell-mediated cytotoxicity. J. Immunol. 156, 3678-3686 (1996).

105 Prassas, I. \& Diamandis, E. P. Novel therapeutic applications of cardiac glycosides. Nat. Rev. Drug. Discov. 7, 926-935 (2008).

106 Kaplan, J. H. Biochemistry of Na,K-ATPase. Ann. Rev. Biochem. 71, 511-535 (2002)

107 Aizman, O., Uhlén, P., Lal, M., Brismar, H. \& Aperia, A. Ouabain, a steroid hormone that signals with slow calcium oscillations. Proc. Natl Acad. Sci. USA 98, 13420-13424 (2001).

108 Miyakawa-Naito, A. et al. Cell signaling microdomain with $\mathrm{Na}, \mathrm{K}$-ATPase and inositol 1,4,5-triphosphate receptor generates calcium oscillations. J. Biol. Chem. 278, 50355-50361 (2003).

$109 \mathrm{Li}$, J., Zelenin, S., Aperia, A. \& Aizman, O. Low doses of ouabain protect from serum deprivation-triggered apoptosis and stimulate kidney cell proliferation via activation of NF-кB. J. Am. Soc. Nephrol. 17, 1848-1857 (2006).

$110 \mathrm{Xie}, \mathrm{Z}$. et al. Intracellular reactive oxygen species mediate the linkage of $\mathrm{Na}^{+} / \mathrm{K}^{+}$ATPase to hypertrophy and its marker genes in cardiac myocytes. J. Biol. Chem. 274, 19323-19328 (1999).

$111 \mathrm{Xie}, \mathrm{Z}$. \& Cai, T. Na+ ${ }^{+} \mathrm{K}^{+}-$ATPase-mediated signal transduction: from protein interaction to cellular function. Mol. Interv. 3, 157-168 (2003).

112 Manna, S. K., Sah, N. K., Newman, R. A., Cisneros, A. \& Aggarwal, B. B. Oleandrin suppresses activation of nuclear transcription factor- $\mathrm{KB}$, activator protein-1, and c-Jun $\mathrm{NH}_{2}$-terminal kinase. Cancer Res. 60, 3838-3847 (2000).

113 Sreenivasan, Y., Sarkar, A. \& Manna, S. K. Oleandrin suppresses activation of nuclear transcription factor- $\mathrm{\kappa} B$ and activator protein- 1 and potentiates apoptosis induced by ceramide. Biochem. Pharmacol. 66, 2223-2239 (2003).

114 Srivastava, M. et al. Digitoxin mimics gene therapy with CFTR and suppresses hypersecretion of IL-8 from cystic fibrosis lung epithelial cells. Proc. Natl Acad. Sci. USA 101, 7693-7698 (2004).

115 Manna, S. K., Sreenivasan, Y. \& Sarkar, A. Cardiac glycoside inhibits IL-8-induced biological responses by downregulating IL-8 receptors through altering membrane fluidity. J. Cell. Physiol. 207, 195-207 (2006).

116 Tabary, O. et al. Calcium-dependent regulation of NF-kB activation in cystic fibrosis airway epithelial cells. Cell Signal. 18, 652-660 (2006).

117 Yang, Q. et al. Cardiac glycosides inhibit TNF- $\alpha / N F-\kappa B$ signaling by blocking recruitment of TNF receptor-associated death domain to the TNF receptor. Proc. Natl Acad. Sci. USA 102, 9631-9636 (2005).

118 Jagielska, J., Salguero, G., Schieffer, B. \& Bavendiek, U. Digitoxin elicits antiinflammatory and vasoprotective properties in endothelial cells: therapeutic implications for the treatment of atherosclerosis? Atherosclerosis 206, 390-396 (2009).

$119 \mathrm{Fu}, \mathrm{L}$. et al. Three new triterpenes from Nerium oleander and biological activity of the isolated compounds. J. Nat. Prod. 68, 198-206 (2005).

120 Zhao, M. et al. Taraxasterane- and ursane-type triterpenes from Nerium oleander and their biological activities. J. Nat. Prod. 69, 1164-1167 (2006).

121 Bai, L. et al. Bioactive pregnanes from Nerium oleander. J. Nat. Prod. 70, 14-18 (2007).

122 Zhao, M. et al. Bioactive cardenolides from the stems and twigs of Nerium oleander. J. Nat. Prod. 70, 1098-1103 (2007).

123 Wang, L. et al. Bioactive triterpene saponins from the roots of Phytolacca americana. J. Nat. Prod. 71, 35-40 (2008).

124 Takada, Y. et al. Odoroside $\mathrm{A}$ and ouabain inhibit $\mathrm{Na}^{+} / \mathrm{K}^{+}$-ATPase and prevent $\mathrm{NF}-\mathrm{KB}^{-}$ inducible protein expression by blocking $\mathrm{Na}^{+}$-dependent amino acid transport. Biochem. Pharmacol. 78, 1157-1166 (2009).

125 Hyde, R., Taylor, P. M. \& Hundal, H. S. Amino acid transporters: roles in amino acid sensing and signalling in animal cells. Biochem. J. 373, 1-18 (2003).

126 Sugimoto, H. et al. E-73, an acetoxyl analogue of cycloheximide, blocks the tumor necrosis factor-induced NF-kB signaling pathway. Biochem. Biophys. Res. Commun. 277, 330-333 (2000).

127 Kadohara, K. et al. Acetoxycycloheximide (E-73) rapidly induces apoptosis mediated by the release of cytochrome $c$ via activation of c-Jun $\mathrm{N}$-terminal kinase. Biochem. Pharmacol. 69, 551-560 (2005).

128 Ogura, H. et al. Ectodomain shedding of TNF receptor 1 induced by protein synthesis inhibitors regulates TNF- $\alpha$-mediated activation of NF- $\mathrm{KB}$ and caspase-8. Exp. Cell Res. 314, 1406-1414 (2008).

129 Schlöndorff, J. \& Blobel, C. P. Metalloprotease-disintegrins: modular proteins capable of promoting cell-cell interactions and triggering signals by protein-ectodomain shedding. J. Cell Sci. 112, 3603-3617 (1999).

130 Moss, M. L., White, J. M., Lambert, M. H. \& Andrews, R. C. TACE and other ADAM proteases as targets for drug discovery. Drug Discov. Today 6, 417-426 (2001).

131 lordanov, M. S. et al. Ribotoxic stress response: activation of the stress-activated protein kinase JNK1 by inhibitors of the peptidyl transferase reaction and by sequence-specific RNA damage to the $\alpha$-sarcin/ricin loop in the 28S rRNA. Mol. Cell. Biol. 17, 3373-3381 (1997)

132 Sidhu, J. S. \& Omiecinski, C. J. Protein synthesis inhibitors exhibit a nonspecific effect on phenobarbital-inducible cytochrome $\mathrm{P} 450$ gene expression in primary rat hepatocytes. J. Biol. Chem. 273, 4769-4775 (1998). 
133 Shifrin, V. I. \& Anderson, P. Trichothecene mycotoxins trigger a ribotoxic stress response that activates c-Jun $\mathrm{N}$-terminal kinase and p38 mitogen-activated protein kinase and induces apoptosis. J. Biol. Chem. 274, 13985-13992 (1999).

134 Ogura, $H$. et al. ERK and p38 MAP kinase are involved in downregulation of cell surface TNF receptor 1 induced by acetoxycycloheximide. Int. Immunopharmacol. 8 , 922-926 (2008).

135 Kadohara, K. et al. Caspase- 8 mediates mitochondrial release of pro-apoptotic proteins in a manner independent of its proteolytic activity in apoptosis induced by the protein synthesis inhibitor acetoxycycloheximide in human leukemia Jurkat cells. J. Biol. Chem. 284, 5478-5487 (2009).

136 Fan, H. \& Derynck, R. Ectodomain shedding of TGF- $\alpha$ and other transmembrane proteins is induced by receptor tyrosine kinase activation and MAP kinase signaling cascades. EMBO J. 18, 6962-6972 (1999).

137 Díaz-Rodríguez, E., Montero, J. C., Esparís-Ogando, A., Yuste, L. \& Pandiella, A. Extracellular signal-regulated kinase phosphorylates tumor necrosis factor $\alpha$-converting enzyme at threonine 735: a potential role in regulated shedding. Mol. Biol. Cell 13, 2031-2044 (2002).

138 Weskamp, G. et al. Evidence for a critical role of the tumor necrosis factor $\alpha$ convertase (TACE) in ectodomain shedding of the p75 neurotrophin receptor (p75 NTR). J. Biol. Chem. 279, 4241-4249 (2004).
139 Soond, S. M., Everson, B., Riches, D. W. H. \& Murphy, G. ERK-mediated phosphorylation of Thr735 in TNF $\alpha$-converting enzyme and its potential role in TACE protein trafficking. J. Cell Sci. 118, 2371-2380 (2005)

140 Deng, X. et al. p38 Mitogen-activated protein kinase-dependent tumor necrosis factor$\alpha$-converting enzyme is important for liver injury in hepatotoxic interaction between lipopolysaccharide and ranitidine. J. Pharmacol. Exp. Ther. 326, 144-152 (2008).

141 Kopp, E. \& Ghosh, S. Inhibition of NF-kB by sodium salicylate and aspirin. Science 265, 956-959 (1994).

142 Yin, M. J., Yamamoto, Y. \& Gaynor, R. B. The anti-inflammatory agents aspirin and salicylate inhibit the activity of IкB kinase- $\beta$. Nature 396, 77-80 (1998).

143 Schwenger, P., Alpert, D., Skolnik, E. Y. \& Vilcek, J. Activation of p38 mitogenactivated protein kinase by sodium salicylate leads to inhibition of tumor necrosis factor-induced $\mathrm{I} \kappa \mathrm{B} \alpha$ phosphorylation and degradation. Mol. Cell. Biol. 18, 78-84 (1998).

144 Alpert, D., Schwenger, P., Han, J. \& Vilcek, J. Cell stress and MKK6b-mediated p38 MAP kinase activation inhibit tumor necrosis factor-induced IKB phosphorylation and NF-kB activation. J. Biol. Chem. 274, 22176-22183 (1999).

145 Madge, L. A., Sierra-Honigmann, M. R. \& Pober, J. S. Apoptosis-inducing agents cause rapid shedding of tumor necrosis factor receptor 1 (TNFR1). J. Biol. Chem. 274, 13643-13649 (1999). 